\title{
Current understanding and challenges of polymeric photocatalysts for solar-driven hydrogen generation
}

3

4

Yiou Wang ${ }^{\mathrm{a}}$, Anastasia Vogel ${ }^{\mathrm{b}}$, Michael Sachs ${ }^{\mathrm{c}}$, Reiner Sebastian Sprick ${ }^{\mathrm{b}}$, Liam Wilbraham ${ }^{\mathrm{d}}$, Savio J. A. Moniz ${ }^{\mathrm{a}}$, Robert Godin ${ }^{\mathrm{ce}}$, Martijn A. Zwijnenburg ${ }^{\mathrm{d}^{*}}$, James R. Durrant ${ }^{\mathrm{c}^{*}}$, Andrew I. Cooper ${ }^{\mathrm{b}^{*}}$ Junwang Tang ${ }^{\mathrm{a}^{*}}$

a. Department of Chemical Engineering, University College London, Torrington Place, London, WC1E 7JE, UK. Email: junwang.tang@ucl.ac.uk

b. Department of Chemistry and Centre for Materials Discovery, University of Liverpool, Crown Street, Liverpool, L69 7ZD, UK. E-mail: aicooper@liverpool.ac.uk

c. Department of Chemistry and Centre for Plastic Electronics, Imperial College London, South Kensington Campus, London SW7 2AZ, U.K. E-mail: j.durrant@imperial.ac.uk

d. Department of Chemistry, University College London, 20 Gordon Street, London WC1H 0AJ, U.K. E-mail: m.zwijnenburg@ucl.ac.uk

e. Department of Chemistry, The University of British Columbia, Okanagan Campus, 3247 University Way, Kelowna, British Columbia V1V 1V7, Canada

The use of hydrogen as a fuel, when generated from water using semiconductor photocatalysts and driven by sunlight, is a sustainable alternative to fossil fuels. Polymeric photocatalysts are based on earth-abundant elements and have the advantage over their inorganic counterparts that their electronic properties are easily tuneable through molecular engineering. Polymeric photocatalysts have developed rapidly over the last decade, resulting in the discovery of many active materials. However, our understanding of the key properties underlying their photoinitiated redox processes has not kept pace, and this impedes further progress to generate cost-competitive technologies. Here, we discuss state of the art polymeric photocatalysts and our microscopic understanding of their activities. We conclude with a discussion of five outstanding challenges in this field: nonstandardized reporting of activities, limited photochemical stability, insufficient knowledge of reaction mechanisms, balancing charge carrier lifetimes with catalysis timescales, and the use of unsustainable sacrificial reagents.

\section{Introduction}

With the global reliance on non-renewable fossil fuels and increasing concern over their impact on climate, there has never been greater urgency to secure alternative clean and renewable energy supplies. Solar hydrogen has attracted much interest because of the abundance of solar energy and the cleanliness and high gravimetric energy density of hydrogen fuel. To scale-up photocatalytic water splitting to produce renewable hydrogen, we require a low-cost, earth-abundant photocatalyst with a $\sim 10 \%$ solar-to-hydrogen (STH) energy conversion efficiency ${ }^{1}$. Considering that nearly half of the energy in the sunlight that reaches the earth surface comes from visible light photons $(400-700 \mathrm{~nm})$, their efficient use is one of the biggest challenges ${ }^{2}$. The long-standing target here is to find efficient, reasonably-priced semiconductor photocatalysts that can thermodynamically drive both proton reduction to hydrogen and water oxidation to oxygen, while staying chemically and photolytically stable over long periods ${ }^{3}$. Four decades of extensive exploration into inorganic semiconductor photocatalysts - mostly metal oxides - has demonstrated that tuning their properties is challenging ${ }^{4}$. By contrast, conjugated polymeric semiconductors have a potential advantage of easy-to-tune properties through synthetic control. This tuneability and their proven performance in fields including solar cells ${ }^{5}$, photoelectrochemical devices ${ }^{6}$ and light-emitting diodes ${ }^{7}$, make organic materials attractive alternatives to inorganic semiconductor photocatalysts.

The first reports on conjugated polymer photocatalysts date back to the late 1980s when Japanese researchers demonstrated that poly $(p \text {-phenylene })^{8,9}$ could reduce protons to hydrogen under illumination in the presence of sacrificial electron donors. In 2009 , polymeric carbon nitride $\left(\mathrm{CN}_{\mathrm{x}} \mathrm{H}_{\mathrm{y}}\right)$ was shown to evolve hydrogen from a $10 \mathrm{vol} \%$ triethanolamine (TEOA) aqueous solution and oxygen from an $0.01 \mathrm{M}$ silver nitrate aqueous solution under visible-light illumination ${ }^{10}$. This report triggered a massive interest in $\mathrm{CN}_{\mathrm{x}} \mathrm{H}_{\mathrm{y}}$ for hydrogen production and the development of new polymeric 
photocatalysts, including conjugated poly(azomethine) networks, pyrene-based conjugated microporous polymers (CMPs), covalent triazine-based frameworks (CTFs), covalent organic frameworks (COFs), and planarized-fluorene-based conjugated polymers, to name a few ${ }^{11-15}$. Recently, overall water splitting (OWS) using polymeric photocatalysts has also been claimed ${ }^{16-19}$, albeit at impractically low efficiencies.

Despite the recent interest in polymeric photocatalysts, and particularly reduction photocatalysts for hydrogen generation, we have yet to reach an understanding of their photophysics comparable to that developed for organic photovoltaics (OPVs) and metal oxide photocatalysts. Even factors well-known to influence the performance of OPVs and metal oxides, such as defects and charge trapping, have only just started to receive attention. The intimate interaction of the sacrificial electron donor and/or co-catalysts on the surface of polymer photocatalysts most likely affects their charge transfer kinetics and possibly exciton dissociation, yet little is known to date. The structural tunability of polymers and the multitude of electron donor-polymer combinations suggests that significant efforts are needed to understand their association and its impact fully. Difficulties in producing samples with identical physical properties such as molecular weight, degree of branching, and terminations, will likely complicate the comparison of results between different laboratories. Furthermore, it is still debatable whether such materials can directly drive the multi-redox chemistry of water oxidation and reduction or whether co-catalysts are always required ${ }^{14,20}$.

Here we discuss state-of-the-art polymeric photocatalysts for the hydrogen and oxygen evolution half reactions. We also explore design rules for these systems and how they can be characterised through spectroscopy. Furthermore, we discuss challenges facing this field, such as uncertainties surrounding the functional characterisation of photocatalysts, where the mechanism for hydrogen production is usually unknown.

\section{Framework for understanding polymer photocatalytic activity}

A photocatalytic reaction is initiated by light absorption to generate excited electron-hole pairs (excitons), followed by their separation into free charges, which ultimately drive redox reactions. The amount of light that a photocatalyst absorbs, and thus the number of charges it can generate, is determined by the overlap of its absorption spectrum with the irradiance spectrum of the light source.

In contrast to polymers in solution, absorption spectra of solid polymers generally have a block-like shape $^{21}$, and their light absorption is therefore often simplified to a consideration of the optical gap. The optical gap of a semiconductor is the minimum energy (longest wavelength) that a photon requires to generate excitons and can vary sharply from polymers to polymers. For example, poly $(p-$ phenylene) has an optical gap in the violet $\left(\mathrm{E}_{\text {gap }} \sim 3 \mathrm{eV}, \lambda_{\text {edge }} \sim 420 \mathrm{~nm}\right)^{8}$, just barely in the visible range of the spectrum, while poly(thiophene) already starts absorbing in the near-infrared $(\sim 1.5 \mathrm{eV}$, $830 \mathrm{~nm})^{22}$. Shifting the optical gap to the red generally results in more absorbed photons, thus generating more excitons and more free charge carriers if these excitons dissociate.

Light absorption by organic materials typically produces Frenkel excitons with binding energies that are more than an order of magnitude larger than $k T$ at room temperature ${ }^{23}$. This strong interaction tends to prevent spontaneous exciton dissociation and opens loss pathways such as re-emission of light (photoluminescence) or internal conversion into heat/phonons. Spontaneously separated charges may also relax to the ground state through electron-hole recombination or reassociate into excitons. The large binding energy means that excitons usually must diffuse to an interface- such as the polymer-solution interface - to dissociate, where one of the formed charge carriers takes part in a solution reaction, and the other remains on the polymer, poised to undergo a subsequent reaction. These charge carriers must possess a sufficiently high driving force for a targeted reaction such as proton reduction or the oxidation of water/sacrificial electron donors.

Free electrons in a polymer can thermodynamically drive the reduction of protons to molecular hydrogen if the electron affinity (EA) of the polymer, when expressed as a redox potential, is more negative than the potential of the proton reduction reaction $\left(\mathrm{H}^{+}(\mathrm{aq})+\mathrm{e}^{-} \rightarrow 1 / 2 \mathrm{H}_{2}(\mathrm{~g}), \mathrm{E}=-0.41 \mathrm{~V}\right.$ vs. SHE at pH 7). Similarly, free holes can drive the oxidation of water if the ionisation potential (IP) of 
the polymer is more positive than the potential of the overall oxidation of water $\left(\mathrm{O}_{2}(\mathrm{~g})+4 \mathrm{H}^{+}(\mathrm{aq})+\right.$ $4 \mathrm{e}^{-} \rightarrow 2 \mathrm{H}_{2} \mathrm{O}(1), \mathrm{E}=+0.82 \mathrm{~V}$ vs. SHE at $\mathrm{pH} 7$ ). Hence, the EA and the IP of the polymer should straddle both reactions to work as an OWS photocatalyst (Fig. 1). In the case of excitons, the corresponding IP and EA potentials are labelled as IP ${ }^{*}$ for reduction and $\mathrm{EA}^{*}$ for oxidation (the asterisk denotes that an exciton provides the electron or hole). The oxidation of sacrificial donors like triethylamine (TEA) is thermodynamically less demanding than for water (diethylamine (aq) + acetaldehyde $(\mathrm{aq})+2 \mathrm{H}^{+}(\mathrm{aq})+2 \mathrm{e}^{-} \rightarrow$ triethylamine $(\mathrm{aq})+\mathrm{H}_{2} \mathrm{O}(1), \mathrm{E}=-0.72 \mathrm{~V}$ vs SHE at $\mathrm{pH} 11.5^{21}$, the likely $\mathrm{pH}$ of a triethylamine solution). It is also kinetically faster because two holes rather than four are required. As a result, the activity of polymers for hydrogen evolution is often tested in the first instance using such sacrificial donors, rather than attempting OWS.

It is known from the literature on $\mathrm{OPVs}^{24}$ that the exciton diffusion length (the distance an exciton travels before decaying back to the electronic ground state) is typically much shorter than the optical absorption depth (the distance light penetrates a material). Rapid charge separation across the interface is promoted by a large interfacial area between donor and acceptor domains, but the decrease of pure domains that serve as long-range selective charge transport channels can also lead to more rapid geminate recombination of electron-hole formed from the same absorbed photon ${ }^{25}$. For polymeric photocatalysts, reduction of the typical particle/domain size, or increased solution permeability, should help in minimising the loss of excitons before they can dissociate at the polymer/solution interface. The interaction between the polymer and water (i.e., the wettability) can be expected to influence the activity of these materials, particularly for OWS. For linear polymers, contact angle values (lower angles correspond to better wetting) measured for pure water are reported to range from $\sim 90^{\circ}$ for purely hydrocarbon polymers ${ }^{26}$, such as poly ( $p$-phenylene), to $\sim 60^{\circ}$ or lower for polymers containing heteroatoms ${ }^{27}$, such as poly $\left(2,5\right.$-pyridine) and undoped $\mathrm{CN}_{\mathrm{x}} \mathrm{H}_{\mathrm{y}}$, or even lower for suitably doped $\mathrm{CN}_{\mathrm{x}} \mathrm{H}_{\mathrm{y}}{ }^{28}$

\subsection{Characterisation of the activity of polymers}

The activity of a photocatalyst for a targeted reaction can be quantified by measuring the formation rate of the product; for example, the hydrogen evolution rate. Importantly, the rates strongly depend on experimental conditions such as the spectrum and intensity of the light source. To further complicate things, rates are reported with or without considering the mass of photocatalyst $\left(\mu \mathrm{mol} \mathrm{h}{ }^{-1} \mathrm{~g}^{-1}\right.$ vs $\left.\mu \mathrm{mol} \mathrm{h}^{-1}\right)$. We provide some clarification of the experimental conditions in our overview tables below. However, we note that spectrum and output intensity even vary for different models of nominally the same light source (e.g., different $300 \mathrm{~W}$ Xe light sources). In addition, the lack of standards for the different lamp-to-sample distances and use of focusing/collimating optics make direct comparisons between reports from different groups difficult. Complimentary apparent quantum yield (AQY) measurements directly relate the amount of formed product to the amount of incoming monochromatic photons, which improves comparability of activities; this makes AQY a preferable and more reliable metric than hydrogen evolution rate. AQY for hydrogen evolution is calculated as the ratio of the number of reacted electrons $(2 \times$ number of hydrogen molecules produced) to the number of incident photons of defined energy:

$$
A Q Y=\frac{2 \times n_{H_{2}}}{n_{\text {photon }}}
$$

Even with well-defined illumination conditions, AQY (and hydrogen evolution rate) measurements are still affected by other reaction parameters such as photocatalyst concentration, sacrificial donor used, mixing, the bandwidth of a band filter and reactor pressure $\left(p_{\text {initial }}\right)$. For instance, a reduced headspace pressure suppresses back reactions compared to ambient pressure, often improving the hydrogen evolution yield significantly. Other factors, such as the addition of phosphate salt, can enhance the hydrogen evolution yield by accelerating the proton reduction and TEOA oxidation ${ }^{29,30}$. Therefore, all these factors should be carefully considered when comparing the performance of different photocatalysts. 


\section{Performance of polymeric photocatalysts}

3

\subsection{Carbon nitrides and their photocatalytic activity}

Carbon nitrides are a family of triazine or heptazine-based polymers containing carbon and nitrogen, which is often referred to in the literature as graphitic carbon nitride $\left(\mathrm{g}-\mathrm{C}_{3} \mathrm{~N}_{4}\right)$, which would be a heptazine-based layered crystalline structure (Fig. 2, 1). However, both characterisation reported and calculations of the $\mathrm{CN}_{\mathrm{x}} \mathrm{H}_{\mathrm{y}}$ phase diagram ${ }^{31}$ show that ideal $\mathrm{g}-\mathrm{C}_{3} \mathrm{~N}_{4}$ is unlikely to form under the synthetic conditions employed so far for photocatalytically active samples. In practice, materials of relevance to photocatalysis, even if referred to as $\mathrm{g}-\mathrm{C}_{3} \mathrm{~N}_{4}$, contain significant amounts of hydrogen ${ }^{32}$ and appear to consist of melon ( 2 in Fig. 2) ${ }^{33,34}$. Melon is a linear polymer formed of heptazine units linked through amine (-NH-) bridges with a solid-state structure that is stabilised by intermolecular hydrogen bonds involving the amine groups. Photocatalytically active carbon nitride materials are often poorly crystalline or X-ray amorphous and are more accurately represented by $\mathrm{CN}_{\mathrm{x}} \mathrm{H}_{\mathrm{y}}$ based on both experimental characterisation and modelling. Alternatively, materials prepared using molten salt as the reaction medium can yield a crystalline, layered poly(triazine imide) structure ${ }^{35}$ in which some of the salt ions are incorporated ( $\mathbf{3}$ in Fig. 2).

Table 1 summarises representative examples of $\mathrm{CN}_{\mathrm{x}} \mathrm{H}_{\mathrm{y}}$ photocatalysts for hydrogen or oxygen evolution. Systems with AQYs larger than a few percentage are mostly reported in the presence of a sacrificial scavenger and a co-catalyst (e.g. Pt or $\mathrm{Ru}$, usually by photodeposition). Among various pristine $\mathrm{CN}_{\mathrm{x}} \mathrm{H}_{\mathrm{y}}$ materials synthesised from common precursors, urea-derived materials exhibit slightly wider optical gaps $(2.9-3.0 \mathrm{eV})$ than their dicyandiamide/melamine-derived counterparts $(2.7 \sim 2.8 \mathrm{eV})$, and represent the benchmark for efficiency, perhaps due to a higher degree of polymerisation ${ }^{36,37}$. Recently, several other organic precursors (e.g., semicarbazide hydrochloride, 5-aminotetrazole) were reported to produce $\mathrm{CN}_{\mathrm{x}} \mathrm{H}_{\mathrm{y}}$ with improved performance ${ }^{28,30}$. A range of synthetic modifications to promote, for example, charge separation, have been proposed ${ }^{38}$ and used to achieve higher AQYs (generally for light in the range of 395 420 nm). Such engineering strategies include increasing the degree of polymerisation ${ }^{36}$, nanosheet fabrication $^{39}$, use of templates ${ }^{40}$, fabrication in molten salts ${ }^{41}$, creating $p$-n homojunction ${ }^{42}$, and selective doping $^{43,44}$. Another emerging approach to control the properties of $\mathrm{CN}_{x} \mathrm{H}_{y}$ is the utilisation of selfassembled supramolecular structures as reactants ${ }^{45-48}$, such as using of halogen-based assemblies ${ }^{49-52}$ and supramolecular single crystals ${ }^{53-55}$. Interestingly, a few $\mathrm{CN}_{\mathrm{x}} \mathrm{H}_{\mathrm{y}}$ materials with controlled terminal groups, including cyanamide, urea and hydroxyl species ${ }^{28,56,57}$, have boosted HERs, suggesting that terminal groups in $\mathrm{CN}_{\mathrm{x}} \mathrm{H}_{\mathrm{y}}$ structures can play an important role. So far, materials prepared via the molten salt approach have exhibited benchmark AQYs of 57 65\% at $420 \mathrm{~nm}$ measured under reduced pressure in a phosphate environment, although their stability is seldom reported $30,37,58,59$.

Meanwhile, to better match light absorption and solar spectrum, strategies have been devised to narrow the optical gap of $\mathrm{CN}_{\mathrm{x}} \mathrm{H}_{\mathrm{y}}{ }^{60-68}$. Recently, location-controlled doping of $\mathrm{CN}_{\mathrm{x}} \mathrm{H}_{\mathrm{y}}$ (e.g., selective linker/terminal replacement, surface layer doping) was reported to not only enhance charge separation but also stepwise narrow the optical gap to below $2 \mathrm{eV}$, leading to enhanced HERs and a benchmark AQY of $2.1 \%$ at 500 $\mathrm{nm}$ measured at ambient conditions ${ }^{28,69}$. Despite these impressive advances in hydrogen evolution rate performance, fundamental understanding of $\mathrm{CN}_{\mathrm{x}} \mathrm{H}_{\mathrm{y}}$ photocatalytic activity is still relatively limited, as we discuss further below.

Compared to proton reduction, there have been far fewer reports on water oxidation ${ }^{69-72}$ and $\mathrm{OWS}^{3,16,18,19}$ using $\mathrm{CN}_{\mathrm{x}} \mathrm{H}_{\mathrm{y}}$, most likely due to the inherent kinetic and energetic challenges of water oxidation. $\mathrm{CN}_{\mathrm{x}} \mathrm{H}_{\mathrm{y}}$ was the first polymer to perform OWS in Z-scheme systems ${ }^{3,73}$ or with suitable co-catalysts $\left(e . g\right.$., $\mathrm{Pt} / \mathrm{PtO}_{\mathrm{x}}$, $\mathrm{Pt} / \mathrm{CoP})^{18,19}$. In a Z-scheme system, $\mathrm{CN}_{\mathrm{x}} \mathrm{H}_{\mathrm{y}}$ and $\mathrm{WO}_{3}\left(\right.$ or $\mathrm{BiVO}_{4}$ ) worked as reduction and oxidation photocatalysts, with $\mathrm{I}^{-} / \mathrm{IO}_{3}^{-}$(or $\mathrm{Fe}^{2+} / \mathrm{Fe}^{3+}$ ) as redox mediators, respectively. Later on, reduced graphene oxide was reported as a shuttle in $\mathrm{CN}_{\mathrm{x}} \mathrm{H}_{\mathrm{y}} / \mathrm{WO}_{3}$ heterojunction for OWS. Remarkably, carbon-quantumdots (QD) cocatalysts are suggested to facilitate charge separation and decompose kinetically favourable $\mathrm{H}_{2} \mathrm{O}_{2}{ }^{74}$ to $\mathrm{O}_{2}$ via a two-electron process, bypassing the slow four-hole kinetics of direct oxidation of $\mathrm{H}_{2} \mathrm{O}$ to $\mathrm{O}_{2}$. The reported STH efficiency of $2 \%$ on $\mathrm{QD} / \mathrm{CN}_{\mathrm{x}} \mathrm{H}_{\mathrm{y}}$ composite is notable ${ }^{16}$, although this has proved challenging to reproduce ${ }^{16,75}$. 


\subsection{Synthesis and photocatalytic activity of organic polymers}

4 Despite the substantial progress made in tailoring the (photophysical) properties of $\mathrm{CN}_{\mathrm{x}} \mathrm{H}_{\mathrm{y}}$ by tuning 5 the synthetic routes and/or post-synthetic modifications, the degree of control and synthetic diversity are inherently limited by the reaction conditions required to prepare the materials. This is less of an issue when preparing conjugated polymers via metal-catalysed coupling reactions. Reaction conditions can be relatively mild, and many functional groups in the reactants can be tolerated. This allows the study of families of materials using related building blocks and, hence, the study of structure-performance relationships. While there are still limits to synthetic control in such polymers-for example, regarding molecular weight, architecture, and monomer sequence distribution in copolymers - there is, in general, a broader scope for molecular engineering of a specific function in polymers than in materials synthesised at a high temperature, such as $\mathrm{CN}_{\mathrm{x}} \mathrm{H}_{\mathrm{y}}$. Tables 2 and 3 give an overview of reported polymer-based materials (linear and CTF in Table 2; CMP and COF in Table 3) for hydrogen and oxygen evolution. The values provided in this table are intended to provide a summary of the variety of reported materials and their properties, rather than a numerical comparison of their "success" as photocatalysts. Note that there is no agreement upon systematic nomenclature in this field nor a conclusive analytical portfolio for a full characterisation of these (mostly) insoluble materials. Materials are sorted by decreasing optical gap values.

\subsection{Linear Polymers}

Poly( $p$-phenylene) was shown to evolve hydrogen under illumination in the presence of sacrificial donors in 1985, the first example of a polymeric photocatalyst ${ }^{8}$. While the reported AQY of $0.03 \%$ was low, the effect of different sacrificial donors and additional doping with precious metals was already investigated at that time ${ }^{8,9,76}$. Shortly afterwards, a bipyridine-based linear polymer was shown to reduce protons to hydrogen under illumination using triethylamine as a sacrificial donor; the hydrogen evolution rate increased by two orders of magnitude in the presence of $\mathrm{RuCl}_{3}{ }^{77}$. More recently, the use of linear homo- and co-polymers (Fig. 3) prepared through coupling reactions have received renewed attention as photocatalysts. For example, a series of photocatalytically active phenyl-co-polymers with fluorene derivatives were reported, the most active of which, a co-polymer of phenylene and dibenzo[b,d]thiophene sulfone (P7), was significantly more active than poly $(p \text {-phenylene })^{15}$. Another photocatalytically active linear co-polymer (B-BT-1,4) ${ }^{78}$ featured alternating electron-donor-acceptor units in the form of phenyl and 2,1,3-benzothiadiazole units. Cobalt-chelating PPDI-bpy (perylenediimide-bipyridine) and PPDT-bpy (benzo [1,2-b:4,5$b$ ]dithiophene- bipyridine) co-polymers were developed, combining a light-harvesting polymeric backbone with molecular catalytic active sites (bpy-metal complex) ${ }^{79}$.

In contrast to the discovery of materials with high photocatalytic activity, the processability of polymeric photocatalysts remains poorly explored for the fabrication of multicomponent and scaled- 
with a branched alkyl chain on the nitrogen and phenylene (P8-s), which can be cast as thin films on glass and remains photocatalytically active in that form ${ }^{80}$. This eliminates the need for mechanical dispersion of the polymer in the aqueous solution. Another approach is the use of stable nanoparticle emulsions (polymer dots, or PDots): for example, a combination of the fluorene-2,1,3benzothiadiazole (PFBT) donor-acceptor polymer with an amphiphilic polystyrene co-polymer was reported with very high initial hydrogen evolution rates ${ }^{75,81}$. While the resulting PDots show an increased activity over the pristine polymer suspensions, the stability of these systems needs to be improved because the materials become photocatalytically inactive within hours. Another issue is that the absolute amounts of hydrogen produced are tiny - a few micromoles of hydrogen - because the concentration of PDots is very low. As such, these high mass-normalised hydrogen evolution rates, while interesting, will be of little practical use unless the approach can be translated into stable systems that generate larger amounts of $\mathrm{H}_{2}$ per unit area irradiated.

\subsection{Polymer networks and frameworks}

Polymer network photocatalysts can be subdivided based on their chemical composition, the degree of conjugation in the polymer beyond the monomeric building blocks, whether they are microporous, and their degree of crystallinity. We discuss here these main sub-groups of photocatalytically active polymer networks.

Covalent triazine-based frameworks (CTFs, Fig. 4) are structurally related to $\mathrm{CN}_{\mathrm{x}} \mathrm{H}_{\mathrm{y}}$ in terms of their high nitrogen content and chemical motifs. However, unlike $\mathrm{CN}_{\mathrm{x}} \mathrm{H}_{\mathrm{y}}, \mathrm{CTFs}$ are accessible both via high-temperature molten salt routes and via low-temperature coupling routes ${ }^{82}$. In the molten salt route, synthetic conditions significantly affect the degree of polymerisation, the presence of defects, and the nature of the terminal groups. For example, it was demonstrated that PTO-300 (similar in nominal structure to CTF-1, discussed below), as synthesised at the relatively low temperature of $300{ }^{\circ} \mathrm{C}$, consisted of small oligomers with higher activities than more highly-polymerised systems prepared at higher temperatures ${ }^{83}$. CTFs prepared at elevated temperatures in salt melts also often undergo partial carbonisation, which might partly explain their lower activities ${ }^{84,85}$. In contrast, structurally analogous CTF-1 obtained by acid-catalysed trimerisation of 1,4-dibenzonitrile at much lower temperatures circumvents such side reactions, and this material showed moderate activity for photocatalytic hydrogen evolution with Pt co-catalyst ${ }^{86}$. CTF-1 was also reported to have limited activity for water oxidation in the presence of silver ions, and $\mathrm{RuO}_{2}{ }^{86}$. Stepwise extension of the organic linker between the triazine units from phenyl (CTF-1) to quarterphenyl (CTF-4) gave an optimum performance for CTF-2 (biphenyl linker) ${ }^{87}$. Interestingly, CTF-2 shows lower but still significant activities even without the addition of Pt co-catalyst, when synthesised via a metalmediated cross-coupling reaction. This suggests that residual Pd from the synthesis acts as a cocatalyst ${ }^{88}$ in line with reports for $\mathrm{CN}_{\mathrm{x}} \mathrm{H}_{\mathrm{y}}{ }^{87,89}$, and consistent with a recent report employing conjugated polymeric photocatalyst nanoparticles ${ }^{20}$. The properties of the CTFs can be further tuned by changing the linker beyond phenyl oligomers; for example, by using thiophene ${ }^{19}$ derivatives or, more exotically, by annealing at high temperature with elemental sulfur, thus incorporating sulfur atoms into the triazine unit ${ }^{90}$. 
1 Related to CTFs are polymers based on triazine rings bridged by disulfide bridges ${ }^{91}\left(\mathrm{C}_{3} \mathrm{~N}_{3} \mathrm{~S}_{3}\right)$ and 2 triazine-based polyimide networks (PI) ${ }^{92}$. Both are active for hydrogen evolution in the presence of a 3 sacrificial donor. The $\mathrm{C}_{3} \mathrm{~N}_{3} \mathrm{~S}_{3}$ polymer also evolves hydrogen from pure water, but this is associated with irreversible oxidation of the disulfide bridges instead of water. Addition of a sacrificial donor quenches this photocorrosion and switches on stable hydrogen evolution.

In contrast to CTFs, conjugated microporous polymers (CMPs, Fig. 5a) can display conjugation across their network ${ }^{93}$. In 2015, a series of heteroatom-free CMPs obtained via Suzuki-Miyaura coupling were reported, where the optical gap was tailored by varying the fractions of different comonomers, which had a substantial effect on the catalytic performance ${ }^{14}$. This was the first example of systematic optical-gap tuning in polymers for photocatalytic hydrogen evolution. Following this, some CMPs with (hetero)aromatic co-monomers have been suggested as photocatalysts for hydrogen evolution in the presence of a sacrificial donor, including conjugated benzene and spirobifluorene ${ }^{94}$, benzodiazole $^{78}$, triazine ${ }^{95}$, naphthalene ${ }^{12}$, and perylene-based networks ${ }^{27,88,96,97,98}$. Some CMPs are porous, branched analogues of linear predecessors, such as the perylenediimide-bipyridine network PCP2-100\%PDI that showed morphological changes upon variation in the stoichiometry of monomers ${ }^{99}$. Nitrogen-containing aza-CMP (Fig. 5b) nanosheets are a rare example of a CMP evolving oxygen from water under illumination in the presence of silver nitrate as a hole scavenger ${ }^{17,100}$. Recently, a combination of aza-CMP and $\mathrm{C}_{2} \mathrm{~N}$ nanosheets ${ }^{101}$, and ethynyl-benzenebased CMPs (PTEB/PTEPB) ${ }^{17,102}$ were claimed to perform OWS and to evolve hydrogen and oxygen simultaneously in a 2:1 ratio. More work is needed to develop these results further.

All of the polymer networks discussed above are substantially amorphous, but covalent organic frameworks (COFs, Fig. 6) ${ }^{103}$, formed through reversible condensation reactions, are typically crystalline. In 2014, a hydrazone-based COF was reported to evolve hydrogen from water under illumination in the presence of a sacrificial donor ${ }^{13}$. The same team subsequently reported a series of photocatalytic 2D azine $\mathrm{COFs}^{104}$ and COFs that could be modified post-synthetically through the incorporation of a molecular co-catalyst ${ }^{105}$. Recently, a diacetylene-based COF that evolves hydrogen was described ${ }^{106}$. Some of us recently reported a crystalline COF based on a benzobis(benzothiophene sulfone) moiety that shows a much higher hydrogen evolution rate than its amorphous or semicrystalline counterparts ${ }^{107}$. Crystalline order in COFs leads to better photocatalytic performance than for amorphous polymer networks, as this order could, in principle better position complementary functionalities . One limitation here is our relatively poor understanding of structurefunction relationships in these materials, which is discussed in the next section.

\section{Physical basis for the photocatalytic activity of polymers}

\subsection{Link between polymer properties and activity}

As discussed in Framework for understanding polymer photocatalytic activity, the observed hydrogen evolution rate of a polymer depends on many material and sample properties. We now briefly review the evidence for this in the literature. First, in the case of the optical gap, it has been 
the hydrogen evolution rate due to improved light harvesting. Contrasting this, the same studies also demonstrate that reducing the thermodynamic driving force for proton reduction and/or water/sacrificial donor oxidation reduces the hydrogen evolution rate. Indeed, we recently reported evidence for a trade-off between the optical gap and the driving force for sacrificial donor oxidation in two different series of materials: an isostructural series of $\mathrm{CTFs}^{87}$ and a series of phenylene-thiophene co-polymers $^{21}$. In both cases, this trade-off results in a maximum in the hydrogen evolution somewhere toward the middle of the materials series. In the case of porosity, in CMPs, where increasing the porosity should result in smaller polymer domains, some studies report no correlation between the degree of porosity and activity ${ }^{14,94}$, while other studies show a marked effect ${ }^{78}$. Possible reasons for this apparent discrepancy are (i) that porosity only becomes relevant when water or the water-SED mixture wets the pores effectively, and (ii) the dominance of another property, such as metal content, which can override the effect of mass diffusion and exciton diffusion length vs domain size. Finally, for linear polymers we recently demonstrated by comparing the activity of ninety-nine polymer photocatalysts that a good dispersibility of the polymer particles, which itself likely correlates with both the wettability and size of the particles, is required for high hydrogen evolution rates. The same study also showed that ranking the activity of the polymers required knowledge of at least four properties, including the EA and dispersability. ${ }^{108}$ In general, photocatalytic activity appears to be a composite of many different materials properties, and the critical property controlling the performance most likely varies from material to material.

The fact that many more polymers of those reviewed above have been reported to evolve hydrogen than to evolve oxygen or to perform OWS can also be at least partly understood when considering material energetics. While most conjugated polymers have sufficiently negative EA to reduce protons at neutral $\mathrm{pH}$, the IP of many conjugated polymers is not sufficiently deep to oxidise water. Some exceptions are certain classes of nitrogen-containing polymers ${ }^{23,109}$, including $\mathrm{CN}_{\mathrm{x}} \mathrm{H}_{\mathrm{y}}{ }^{10,110}$ and $\mathrm{CTFs}^{87}$ (Fig. 4). The latter are indeed those classes for which there is the best evidence for oxygen evolution and water oxidation (see Performance of polymeric photocatalysts).

\subsection{Carbon nitride photophysics}

Intensive investigation of the photophysics of $\mathrm{CN}_{\mathrm{x}} \mathrm{H}_{\mathrm{y}}$ began only recently, and already a few key aspects have emerged. At a fundamental level, it is interesting to consider the question of what is the primary photoexcited species (i.e., excitons vs charge carriers) formed in polymeric $\mathrm{CN}_{\mathrm{x}} \mathrm{H}_{\mathrm{y}}$, as the heptazine units are only cross-conjugated through the secondary or tertiary amino bridges. Initial studies concluded that molecular singlet excitons confined to heptazine units were sufficient to explain the photoluminescence behaviour of $\mathrm{CN}_{\mathrm{x}} \mathrm{H}_{\mathrm{y}}{ }^{111}$, consistent with the low dielectric constant typical of organic materials and the resulting localised Frenkel-like excitons. However, recent photophysical investigations point to the formation of charges (polarons) on time scales $<200 \mathrm{fs}^{112-114}$. While this behaviour is not unprecedented ${ }^{115}$, it is surprising for an organic semiconductor and contrasts to typical cases where efficient charge generation requires the presence of a donor/acceptor junction. This fast charge generation is similar to the effectively direct generation of charges in metal oxides $^{116}$. One possibility is that homojunctions are formed within the material, inducing energy offsets between ordered (crystalline) and disordered (amorphous) domains and charge separation occurs at these interfaces ${ }^{117}$. 
1 An in-depth spectroscopic investigation of urea-derived $\mathrm{CN}_{\mathrm{x}} \mathrm{H}_{\mathrm{y}}$ shed light on the role of low-energy 2 trap states ${ }^{112}$. It was concluded that energy losses of about $1.5 \mathrm{eV}(\sim$ half the absorbed energy) could 3 be attributed to charge trapping, significantly reducing the driving force and rate of charge transfer reactions. Also, an inverse correlation was observed between the charge population on the microsecond timescale and the $\mathrm{H}_{2}$ production rates, not only indicating that deeply-trapped long-lived electrons are unreactive for photoreduction ${ }^{12,118,119}$, but also that charge trapping dictates the photocatalytic activity. The presence of shallow and deep trap states can also be inferred from different decay kinetics of photoinduced absorptions in the visible and NIR regions ${ }^{112,119-121}$. The presence of trap states can also be inferred from red-shifted electroluminescence compared to the PL of $\mathrm{CN}_{\mathrm{x}} \mathrm{H}_{\mathrm{y}}$ thin films ${ }^{7}$ and electrons with millisecond lifetimes have been observed in $\mathrm{CN}_{\mathrm{x}} \mathrm{H}_{\mathrm{y}}$ photoelectrodes ${ }^{122,123}$. A successful strategy to prevent charge trapping into inactive states has been demonstrated by introducing additional components such as red phosphorous crystals ${ }^{124}$, boron ${ }^{28}$, or $\mathrm{TiO}_{2}$ mesocrystals ${ }^{125}$, thus enabling rapid charge extraction that effectively competes with charge trapping.

Consistent with the above discussion, chemical defects play a role in the $\mathrm{CN}_{\mathrm{x}} \mathrm{H}_{\mathrm{y}}$ photophysics. A survey of different heptazine-like molecules revealed that the presence of some chemical moieties significantly increased the hydrogen evolution rate ${ }^{56}$. In particular, a cyanamide terminal group added post-synthetically improved activity by over 12-fold, confirming the applicability of defect engineering. A subsequent study compared the photophysics of amino and cyanamide-terminated $\mathrm{CN}_{\mathrm{x}} \mathrm{H}_{\mathrm{y}}$ and discovered that the increased photoactivity could not be traced to reduced charge recombination, a common assumption, but instead to improved charge transfer efficiency ${ }^{120}$. Given the importance of trap states, it seems likely that the trap state density and energetics are modified by the post-synthetic treatment. $\mathrm{CN}_{\mathrm{x}} \mathrm{H}_{\mathrm{y}}$ with cyanamide terminations also showed surprisingly long-lived electrons with enough chemical potential to drive proton reduction even after 12 hours in the dark ${ }^{56,126}$, not seen for amino-terminated analogues. Similar long-lived electrons (radical anions) were observed in a related $\mathrm{CN}_{\mathrm{x}} \mathrm{H}_{\mathrm{y}}$, potassium PTI, in which some of the bridging amines are deprotonated ${ }^{127}$. These point to the amino groups being involved in the formation of deep electron traps. The activity of cyanamide-terminated $\mathrm{CN}_{\mathrm{x}} \mathrm{H}_{\mathrm{y}}$ was further improved by a factor of two by hydrolysing the cyanamide to a urea moiety ${ }^{57}$, possibly explaining the success of urea itself as the starting material for preparing high activity $\mathrm{CN}_{\mathrm{x}} \mathrm{H}_{\mathrm{y}}{ }^{36}$. The terminations and chemical defects found in $\mathrm{CN}_{\mathrm{x}} \mathrm{H}_{\mathrm{y}}$ may also promote rapid charge separation due to significant energy offsets, but potentially at the expense of reactivity. Understanding the complete influence of $\mathrm{CN}_{\mathrm{x}} \mathrm{H}_{\mathrm{y}}$ terminations and defects will likely lead to novel synthetic procedures for high activity materials with controlled chemical structures.

\subsection{Conjugated polymer photophysics}

Conjugated polymeric photocatalysts currently require the presence of sacrificial reagents for appreciable hydrogen evolution rates ${ }^{128}$. Initial studies on poly(p-phenylene) and poly(pyridine-2,5diyil) oligomers have suggested that photocatalytic reactions proceed via reductive quenching of the photoexcited state in the presence of sacrificial electron donors ${ }^{129-131}$. Such "hole scavenging" results in the generation of long-lived polymer-centred electrons with a sufficiently long lifetime to drive relatively slow multi-electron reactions such as hydrogen evolution (timescale typically milliseconds) ${ }^{132-134}$. The generation of such long-lived charges is similar to that in metal oxide 
1 photocatalysts in the presence of sacrificial reagents ${ }^{135,136}$. In principle, extending the excited state

2 lifetime should increase the efficiency of the scavenging reaction. However, the exciton lifetime does 3 not always correlate with the hydrogen evolution rate ${ }^{94}$. The relatively low photocatalytic AQYs of 4 many conjugated polymers (compare Table 2 to $\mathrm{CN}_{\mathrm{x}} \mathrm{H}_{\mathrm{y}}$ in Table 1) imply low concentrations of active 5 species and generally complicate spectroscopic investigations of their performance. 6 Dibenzo $[b, d]$ thiophene sulfone containing polymers are among the most active conjugated polymers 7 for hydrogen evolution ${ }^{15}$. For these materials, the formation of polymer electrons whose lifetime 8 extended up to milliseconds was observed in the presence of TEA as a sacrificial donor, with an 9 appearance half-time of only $1-2 \mathrm{ps}^{137}$. The yield of these long-lived electrons correlated with 10 hydrogen evolution rates, suggesting these electrons retained sufficient reactivity to drive proton 11 reduction. The polar sulfone group was found to be vital for charge generation due to the localisation of water around the otherwise hydrophobic backbone ${ }^{137}$, suggesting that the wettability of a polymer photocatalyst can also affect its driving force for charge transfer.

\section{Challenges and long-term outlook}

Although substantial progress has been made in the development and understanding of polymer-based photocatalysts for direct hydrogen and oxygen production, we believe there are five major challenges to overcome in this field.

The first challenge is the comparability of the hydrogen and oxygen evolution performance of different materials reported by different groups. As known from the literature on inorganic photocatalysts, the measured hydrogen evolution rates and oxygen-evolution rates depend critically on many specific details of the experimental set-up, such as the spectrum of light source, the filter used, the light intensity at the sample, co-catalyst selection and loading, type and concentration of sacrificial donor used, the sample concentration, and the pressure in the reactor headspace. Suggestions for standardisation of (3D-printable) photoreactor set-ups ${ }^{138,139}$ and reporting of at least AQYs instead of only gas evolution rates ${ }^{140,141}$ can be found in the literature.

A second challenge is the long-term stability of polymeric photocatalysts under operating conditions. In the presence of sacrificial donors, polymers have been shown to operate without appreciable loss of activity for at least days on end. During such extended runs, these polymers evolve much more hydrogen than they contain, proving that the hydrogen evolved does not originate from the polymer itself but water ${ }^{15}$. However, the oxidation of water is more sluggish than that of a sacrificial donor. Therefore, it remains unclear if photocorrosion might become more pronounced under water oxidation conditions. For example, it has been demonstrated experimentally ${ }^{91}$ that a polymer of triazine units linked by disulfide bridges evolves hydrogen without any noticeable degradation in the presence of a sacrificial donor, but that the disulfide bridges are oxidised under illumination in pure water.

The third challenge is to understand better the mechanism by which polymeric photocatalysts evolve hydrogen and/or oxygen and the role played by residual or intentionally added noble metal atoms and defects. Undecorated $\mathrm{CN}_{\mathrm{x}} \mathrm{H}_{\mathrm{y}}$ evolves little hydrogen and almost no oxygen in the absence of cocatalysts. Most polymers prepared via cross-coupling reactions do not require an additional cocatalyst but do contain residual noble metal impurities, e.g., palladium from the Suzuki coupling reaction, which could act as co-catalyst. Total removal of such impurities is near impossible in most cases, and experimental evidence for the effect of the residual metal is mixed. On the one hand, 
1 poisoning experiments for phenyl/pyrene CMPs show no change in hydrogen evolution rates in the 2 presence of carbon monoxide ${ }^{14}$, suggesting that either the role of residual palladium is not critical or 3 that there is palladium inaccessible to the carbon monoxide but still active for hydrogen evolution. It 4 is also possible that subsequent photolysis removes the carbon monoxide poisoning agent and 5 regenerates the metal. Also, Pd was found to be essential for the hydrogen evolution activity of the 6 soluble poly(9,9-dioctylfluorene-alt-benzothiadiazole) $(\mathrm{F} 8 \mathrm{BT})^{20}$. A threshold concentration of 7 palladium above which additional metal (palladium, platinum) does not improve rates any further was 8 observed (in this case as low as $100 \mathrm{ppm})^{20}$, in agreement with work on other $\mathrm{CMPs}^{88,99}$. If some 9 polymers can evolve hydrogen in the absence of a metal co-catalyst, the mechanism by which this 10 happens is unknown. There have been some suggestions from theory ${ }^{17,142}$, but this matter is far from resolved. As discussed above, it has been demonstrated that the nature of the terminal groups influence the activity of $\mathrm{CN}_{\mathrm{x}} \mathrm{H}_{\mathrm{y}}$, and that defect engineering can be used to improve hydrogen evolution rate ${ }^{56,57}$. However, it is not yet clear whether these terminal defects play a more significant role in controlling the charge carrier dynamics within $\mathrm{CN}_{\mathrm{x}} \mathrm{H}_{\mathrm{y}}$ or in promoting efficient interfacial charge transfers, or both. Similarly, the role that possible surface states play in charge transfer reactions involving CMPs has not yet been established.

A fourth challenge, closely connected to the third, is to achieve sufficiently long charge carrier lifetimes without losing too much driving force for interfacial redox reactions. For example, in natural photosynthetic reaction centres, a series of fast energetically-downhill charge transfers increase spatial separation and, hence, the lifetime of the charge-separated states at the expense of the energy stored ${ }^{25}$. Since interfacial reactions such as proton reduction typically take place on microsecond or longer timescales ${ }^{143}$, photoexcited states typically relax and localise prior to electron transfer. As observed for $\mathrm{CN}_{\mathrm{x}} \mathrm{H}_{\mathrm{y}}$, this relaxation (i.e., trapping) process can result in substantial loss of driving force and rate of charge transfer on microsecond timescales ${ }^{112}$. Being able to accurately determine the timescales of relaxation and the excited states involved in interfacial charge transfers, both structurally and energetically, will give us the information needed to engineer improved materials. Progress in controlled synthetic routes and targeted post-synthetic modifications combined with careful combined structural and photophysical characterisations are promising avenues to help us complete the picture of the inner workings of various polymer-based photocatalysts and prepare high-efficiency, low-cost materials.

The final challenge is to avoid the use of uneconomic sacrificial electron donors, either by performing OWS or by oxidising abundant, sustainable scavengers to value-added products. As discussed above, OWS activity has only been reported for a small number of polymers, and the reproducibility of some reports is an open question. The problem here is most likely a combination of bulk electron-hole recombination in single-phase polymers, which very effectively competes with productive use of electrons and holes, and the fact that overall water oxidation requires four holes per molecule of oxygen. To circumvent mostly the same problem, nature uses a two-photocatalyst system instead of single photocatalysts ${ }^{144}$, allowing it to overcome the inevitable back reaction on a single photocatalyst and to achieve efficient charge separation. The highest reported STH efficiency of $1 \%$ for a particulate system was achieved using such a Z-scheme ${ }^{75}$ : much better than typically attained on single photocatalysts. While this was reported using inorganic photocatalysts, a similar approach could be applied to polymeric photocatalysts, and indeed there are reports that polymers can split pure water with close to $1 \%$ STH efficiencies ${ }^{16,17}$. The potential solution is the use of a Z-scheme, where 
electrons and holes are spatially separated after generation on divided sub-systems, thereby reducing the propensity for electron-hole recombination and allowing for longer-lived charge carriers and greater accumulation of holes to overcome the kinetic limitations typically associated with water oxidation.

5

\section{Acknowledgement}

7 Y.W. acknowledges the China Scholarship Council (CSC) for full PhD studentship. The UK 8 Engineering and Physical Sciences Research Council (EPSRC) is acknowledged for funding through 9 grant EP/N004884/1 (for R.S.S., L.W., M.A.Z. and A.I.C.). This work has received funding from the 10 European Union's Horizon 2020 research and innovation programme (Marie-Skłodowska-Curie 11 Individual Fellowship to A.V.) under grant agreement No 796322. M.S. thanks the Imperial College 12 President's PhD Scholarship scheme. R.G. thanks the Fonds de recherche du Québec - Nature et 13 technologies (FRQNT) for postdoctoral support and UBC for startup funds. J.R.D. acknowledges 14 support from ERC AdG Intersolar (291482). Y.W., S.J.A.M. and J.T acknowledge the financial 15 supports from UK EPSRC (EP/N009533/1), Royal Society-Newton Advanced Fellowship grant 16 (NA170422) and the Leverhulme Trust (RPG-2017-122).

\section{Competing interests}

The authors declare no competing interests. 
1 Table 1. Comparison of properties and experimental conditions of exemplary carbon nitride 2 photocatalysts

\begin{tabular}{|c|c|c|c|c|c|c|c|c|c|c|c|}
\hline \multirow[b]{2}{*}{ Properties } & \multicolumn{2}{|c|}{ Optical gap $^{a}$} & \multirow[b]{2}{*}{$p_{\text {initial }}^{b}$} & \multirow{2}{*}{$\begin{array}{l}\text { AQY } / \%{ }^{c} \\
(420 \mathrm{~nm})\end{array}$} & \multirow{2}{*}{$\begin{array}{l}\text { Gas evolution } \\
\text { rates } \\
/ \mu \mathrm{mol} \mathrm{h}^{-1} \mathrm{~g}^{-1 d}\end{array}$} & \multirow{2}{*}{$\begin{array}{l}\text { Reported } \\
\text { stability } \\
/ h^{e}\end{array}$} & \multicolumn{2}{|c|}{ Light source } & \multirow[b]{2}{*}{ Conditions } & \multirow[b]{2}{*}{$\begin{array}{l}\text { Repor } \\
\text { t year }\end{array}$} & \multirow[b]{2}{*}{ Ref. } \\
\hline & $\begin{array}{l}\lambda_{\text {edge }} \\
/ \mathbf{n m}\end{array}$ & $\begin{array}{l}E_{\text {gap }} \\
/ \mathrm{eV}\end{array}$ & & & & & $\begin{array}{l}\text { Power } \\
\text { /W }\end{array}$ & Filter & & & \\
\hline F-doping & 472 & 2.6 & red. & N/A & $\mathrm{H}_{2}: 130$ & N/A & $\begin{array}{l}500 \\
(\mathrm{Xe})\end{array}$ & $>420$ & TEA & 2010 & 65 \\
\hline $\begin{array}{l}\text { Barbituric acid } \\
\text { copolymerizati } \\
\text { on }\end{array}$ & 486 & 2.6 & red. & N/A & $\mathrm{H}_{2}: 294$ & 20 & $\begin{array}{l}300 \\
(\mathrm{Xe})\end{array}$ & $>420$ & TEOA & 2010 & 66 \\
\hline B-doping & 600 & 2.1 & amb. & N/A & $\mathrm{H}_{2}: 510$ & N/A & $\begin{array}{l}300 \\
(\mathrm{Xe})\end{array}$ & $>420$ & TEOA & 2011 & 64 \\
\hline $\begin{array}{l}\text { Aminobenzonit } \\
\text { rile } \\
\text { copolymerizati } \\
\text { on }\end{array}$ & 525 & 2.4 & red. & N/A & $\mathrm{H}_{2}: 1470$ & 20 & $\begin{array}{l}300 \\
(\mathrm{Xe})\end{array}$ & $>420$ & TEOA & 2012 & 67 \\
\hline $\mathrm{H}_{2} \mathrm{O}_{2}$ treateded & 498 & 2.5 & amb. & N/A & $\mathrm{H}_{2}: 375$ & 24 & $\begin{array}{l}300 \\
(\mathrm{Xe}\end{array}$ & $>420$ & TEOA & 2012 & 63 \\
\hline $\begin{array}{l}\mathrm{Co}_{3} \mathrm{O}_{4} / \mathrm{CNS} \\
\text { nanohybrid }\end{array}$ & 440 & 2.8 & red. & 1.1 & $\mathrm{O}_{2}: 502$ & 11 & $\begin{array}{l}300 \\
(\mathrm{Xe})\end{array}$ & $>420$ & $\left|\begin{array}{l}0.01 \mathrm{M} \\
\mathrm{AgNO}_{3} \\
0.2 \mathrm{~g} \mathrm{La}_{2} \mathrm{O}_{3}\end{array}\right|$ & 2012 & 145 \\
\hline Nanosheets & 472 & 2.6 & red. & 3.75 & $\mathrm{H}_{2}: 1860$ & 24 & $\begin{array}{l}300 \\
(\mathrm{Xe})\end{array}$ & $>420$ & TEOA & 2013 & 39 \\
\hline $\begin{array}{l}\text { Highly } \\
\text { polymerised }\end{array}$ & 415 & 3.0 & amb. & $\begin{array}{l}12.5^{g} \\
26.5(400 \mathrm{~nm})\end{array}$ & $\mathrm{H}_{2}: 3327$ & 30 & $\begin{array}{l}300 \\
(\mathrm{Xe})\end{array}$ & $>395$ & TEOA & 2014 & 36 \\
\hline $\mathrm{PTI} / \mathrm{Li}^{+} \mathrm{Cl}^{-}$ & 600 & 2.1 & red. & $15(400 \mathrm{~nm})$ & $\mathrm{H}_{2}: 8160$ & N/A & $\begin{array}{l}300 \\
(\mathrm{Xe})\end{array}$ & $>420$ & TEOA & 2014 & 41 \\
\hline Quantum dots & 650 & 1.9 & amb. & N/A & $\mathrm{H}_{2}: 2757$ & N/A & $\begin{array}{l}300 \\
(\mathrm{Xe})\end{array}$ & $>420$ & TEOA & 2014 & 146 \\
\hline N-doping & 477 & 2.6 & amb. & N/A & $\mathrm{H}_{2}: 554$ & 16 & $\begin{array}{l}300 \\
(\mathrm{Xe})\end{array}$ & $>400$ & TEOA & 2015 & 62 \\
\hline Amorphous & 682 & 1.8 & amb. & N/A & $\mathrm{H}_{2}: 3158$ & 7 & $\begin{array}{l}300 \\
(\mathrm{Xe})\end{array}$ & $>440$ & TEOA & 2015 & 147 \\
\hline $\begin{array}{l}\text { Dispersing Co } \\
\text { in GCN }\end{array}$ & 470 & 2.6 & red. & $\mathrm{N} / \mathrm{A}$ & $\mathrm{O}_{2}: 210$ & 7 & $\begin{array}{l}300 \\
(\mathrm{Xe})\end{array}$ & $>420$ & \begin{tabular}{l|}
$0.01 \mathrm{M}$ \\
$\mathrm{AgNO}_{3}$ \\
$0.2 \mathrm{~g} \mathrm{La}_{2} \mathrm{O}_{3}$
\end{tabular} & 2015 & 72 \\
\hline Phosphate salt & 460 & 2.7 & red. & $\begin{array}{l}26.1 \\
45.7(380 \mathrm{~nm})\end{array}$ & $\mathrm{H}_{2}: 18940$ & 4 & $\begin{array}{l}300 \\
(\mathrm{Xe})\end{array}$ & $>400$ & $\begin{array}{ll}0.20 \quad \mathrm{~mol} \\
\mathrm{~K}_{2} \mathrm{HPO}_{4}\end{array}$ & 2015 & 29 \\
\hline $\begin{array}{l}\text { Heated } \\
\text { melamine } \\
\text { (molten } \\
\text { method) }\end{array}$ & 450 & 2.8 & red. & $\begin{array}{lll}50.7 & \left(\mathrm{H}_{2},\right. & 405 \\
\mathrm{~nm}) & & \end{array}$ & $\mid \begin{array}{l}\mathrm{H}_{2}: 15400 \\
\mathrm{O}_{2}: 140 \quad \text { (full } \\
\text { arc) }\end{array}$ & 20 & $\begin{array}{l}300 \\
(\mathrm{Xe})\end{array}$ & $>400$ & $\begin{array}{l}\mathrm{H}_{2}: \\
\text { mol } \\
\mathrm{K}_{2} \mathrm{HPO}_{4}, \\
\mathrm{O}_{2}: \\
\mathrm{AgNO}_{3} \\
\mathrm{La}_{2} \mathrm{O}_{3}\end{array}$ & 2016 & 58 \\
\hline Cyanamide & 500 & 2.5 & amb. & $9.3(400 \mathrm{~nm})$ & $\mathrm{H}_{2}: 1235$ & 100 & 300 & AM 1.5 & methanol & 2016 & 56 \\
\hline
\end{tabular}




\begin{tabular}{|c|c|c|c|c|c|c|c|c|c|c|c|}
\hline defects & & & & & & & $(\mathrm{Xe})$ & & & & \\
\hline P-doping & 487 & 2.5 & amb. & 5.8 & $\mathrm{H}_{2}: 670$ & 20 & $\begin{array}{l}300 \\
(\mathrm{Xe})\end{array}$ & $>420$ & TEOA & 2016 & 61 \\
\hline $\begin{array}{l}\text { Steam } \\
\text { Reforming } \\
\text { nanosheets }\end{array}$ & 441 & 2.8 & red. & $11.3(405 \mathrm{~nm})$ & $\mathrm{H}_{2}: 5222$ & 16 & $\begin{array}{l}300 \\
(\mathrm{Xe})\end{array}$ & $>420$ & TEOA & 2016 & 148 \\
\hline $\begin{array}{l}\text { Linker } \\
\text { controlled }\end{array}$ & 800 & 1.5 & amb. & $\begin{array}{l}10.3 \\
2.1(500 \mathrm{~nm})\end{array}$ & $\begin{array}{l}\mathrm{H}_{2}: 337 \\
\text { no } \mathrm{O}_{2}\end{array}$ & 30 & $\begin{array}{l}300 \\
(\mathrm{Xe})\end{array}$ & $\begin{array}{l}>420, \quad 120 \\
\mathrm{~mW} / \mathrm{cm}^{2}\end{array}$ & $\begin{array}{l}\text { TEOA, } \\
\mathrm{K}_{2} \mathrm{HPO}_{4}\end{array}$ & 2017 & 28 \\
\hline \begin{tabular}{|l|} 
Alkali-Assisted \\
Nitrogen \\
Deficient
\end{tabular} & 525 & 2.4 & amb. & N/A & $\mathrm{H}_{2}: 6900$ & 10 & $\begin{array}{l}300 \\
(\mathrm{Xe})\end{array}$ & $>420$ & $\left|\begin{array}{ll}25 & \text { vol} \% \\
\text { aqueous } \\
\text { lactic }\end{array}\right|$ & 2017 & 60 \\
\hline $\begin{array}{l}\text { Crystalline } \\
\text { Nanosheets }\end{array}$ & 435 & 2.9 & amb. & 8.6 & $\mathrm{H}_{2}: 1060$ & 20 & $\begin{array}{l}300 \\
(\mathrm{Xe})\end{array}$ & $>420$ & $\begin{array}{l}10 \% \\
\text { methanol }\end{array}$ & 2017 & 149 \\
\hline $\begin{array}{l}\text { Co- } \\
\text { condensation } \\
\text { and calcination } \\
\text { in molten salt }\end{array}$ & 484 & 2.6 & red. & 57 & $\mathrm{H}_{2}: 3000$ & N/A & $\begin{array}{l}50 \\
\text { LED }\end{array}$ & $\begin{array}{l}\text { White } \\
\text { LED, >420 }\end{array}$ & $\begin{array}{l}\text { TEOA, } \\
\mathrm{K}_{2} \mathrm{HPO}_{4}\end{array}$ & 2017 & 59 \\
\hline \begin{tabular}{|l|} 
Surface \\
polycondensati \\
on
\end{tabular} & 620 & 2.0 & amb. & N/A & $\mathrm{O}_{2}: 3$ & 2 & 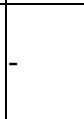 & Visible-light & $\mid \begin{array}{l}\mathrm{O}_{2}: 200 \mathrm{mg} \\
\mathrm{AgNO}_{3}\end{array}$ & 2017 & 70 \\
\hline $\mid \begin{array}{l}\text { Post- } \\
\text { calcination in } \\
\text { molten salts }\end{array}$ & 481 & 2.6 & red. & 60 & $\begin{array}{l}\mathrm{H}_{2}: 11720 \\
\mathrm{O}_{2}: 300\end{array}$ & $\mathrm{~N} / \mathrm{A}$ & $\begin{array}{l}50 \\
\text { LED }\end{array}$ & 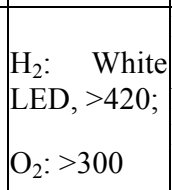 & 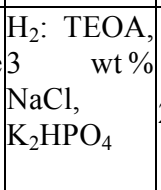 & 2018 & 37 \\
\hline $\begin{array}{l}\text { Gradual carbon } \\
\text { doping }\end{array}$ & 480 & 2.6 & red. & 6.8 & $\mathrm{H}_{2}: 125.1$ & 12 & $\begin{array}{l}300 \\
(\mathrm{Xe})\end{array}$ & $>420$ & TEOA & 2018 & 43 \\
\hline $\begin{array}{l}\text { Formic } \\
\text { treated }\end{array}$ & 650 & 1.9 & amb. & $\begin{array}{l}\mathrm{H}_{2}: 8.6 / 2.5 \text { at } \\
420 / 500 \mathrm{~nm} \text {, } \\
\mathrm{O}_{2}: 4.3 / 1.0 \text { at } \\
420 / 500\end{array}$ & $\begin{array}{l}\mathrm{H}_{2}: 772 \\
\mathrm{O}_{2}: 120\end{array}$ & $\begin{array}{l}\mathrm{H}_{2}: 28 \\
\mathrm{O}_{2}: 18\end{array}$ & $\begin{array}{l}300 \\
(\mathrm{Xe})\end{array}$ & $\begin{array}{l}420-710 \\
100 \\
\mathrm{~mW} / \mathrm{cm}^{2}\end{array}$ & $\begin{array}{l}\mathrm{TEOA}, \\
\mathrm{K}_{2} \mathrm{HPO}_{4} \\
\mathrm{O}_{2}: \mathrm{NaIO}_{3}\end{array}$ & 2018 & 69 \\
\hline $\begin{array}{l}5- \\
\text { aminotetrazole } \\
\text { precursor }\end{array}$ & 496 & 2.5 & red. & 65 & $\mathrm{H}_{2}: 653$ & N/A & & $\begin{array}{l}\text { White } \\
\text { LED, >420; }\end{array}$ & $\begin{array}{l}\mathrm{H}_{2}: \mathrm{TEOA}, \\
\mathrm{K}_{2} \mathrm{HPO}_{4}\end{array}$ & 2019 & 30 \\
\hline
\end{tabular}

$1{ }^{a}$ Values were interconverted according to $\mathrm{E}=\mathrm{h} \times \mathrm{c} / \lambda$ and $\lambda=\mathrm{h} \times \mathrm{c} / \mathrm{E}$ where $\mathrm{h} \times \mathrm{c}$ is $1240 \mathrm{eV} \times \mathrm{nm}$ from 2 data reported in the literature; ${ }^{b}$ Initial pressure in the reaction vial is indicated according to 3 experimental details as ambient (amb., e.g. bubbling of nitrogen) or reduced (red., e.g. evacuation of 4 reaction vessel). ${ }^{c}$ Apparent quantum yield also referred to as quantum efficiency and photonic 5 efficiency in some of the references; ${ }^{d}$ Values were standardised to micromoles per hour and per gram $6\left[\mu \mathrm{mol} \mathrm{h} \mathrm{g}^{-1}\right]$ from data reported in the literature; Oxygen evolution rates (OER) are only given 7 (value or "no $\mathrm{O}_{2}$ ") when experiments were explicitly conducted and reported; ${ }^{e}$ Stable hydrogen 8 production time length where $>75 \%$ of initial activity was retained; ${ }^{f}$ Listed are sacrificial donors and 9 further additives such as additional solvents, and buffers. This condition was applied for $\mathrm{H}_{2}$ evolution 10 if not specified. For $\mathrm{O}_{2}$ production, $\mathrm{AgNO}_{3}$ was used as an electron scavenger if not specified. ${ }^{g}$ 11 Internal quantum yield. 
1 Table 2: Overview of reported linear polymers and covalent triazine frameworks (CTFs) for 2 hydrogen and oxygen evolution.*

\begin{tabular}{|c|c|c|c|c|c|c|c|c|c|c|c|}
\hline \multirow{2}{*}{$\begin{array}{l}\text { Compoun } \\
\text { d }\end{array}$} & \multicolumn{2}{|c|}{ Optical gap ${ }^{a}$} & \multirow{2}{*}{$\begin{array}{l}\text { Metal } \\
\text { cont. }^{b} \\
\text { wt } \%\end{array}$} & \multirow[t]{2}{*}{$p_{\text {initial }}{ }^{c}$} & \multirow{2}{*}{$\begin{array}{l}\text { AQY } \\
d / \% \\
(420 \\
\text { nm) }\end{array}$} & \multirow{2}{*}{$\begin{array}{l}\text { Gas } \\
\text { evolutio } \\
\text { n rates } \text { r }^{e} \\
\mu \text { mol h}^{-1} \\
\mathbf{g}^{-1}\end{array}$} & \multirow{2}{*}{$\begin{array}{l}\text { Stabilit } \\
\text { y / h }\end{array}$} & \multicolumn{2}{|c|}{ Light source } & \multirow{2}{*}{$\begin{array}{l}\text { Conditi } \\
\text { ons }^{f}\end{array}$} & \multirow[t]{2}{*}{ Ref. } \\
\hline & $\begin{array}{l}\lambda_{\text {edge }} \\
/ \mathbf{n m}\end{array}$ & $\begin{array}{l}E_{\text {gap }} \\
/ \mathbf{e V}\end{array}$ & & & & & & $\begin{array}{l}\text { Power } \\
\text { / W }\end{array}$ & $\begin{array}{l}\text { Filter } \\
\text { / nm }\end{array}$ & & \\
\hline
\end{tabular}




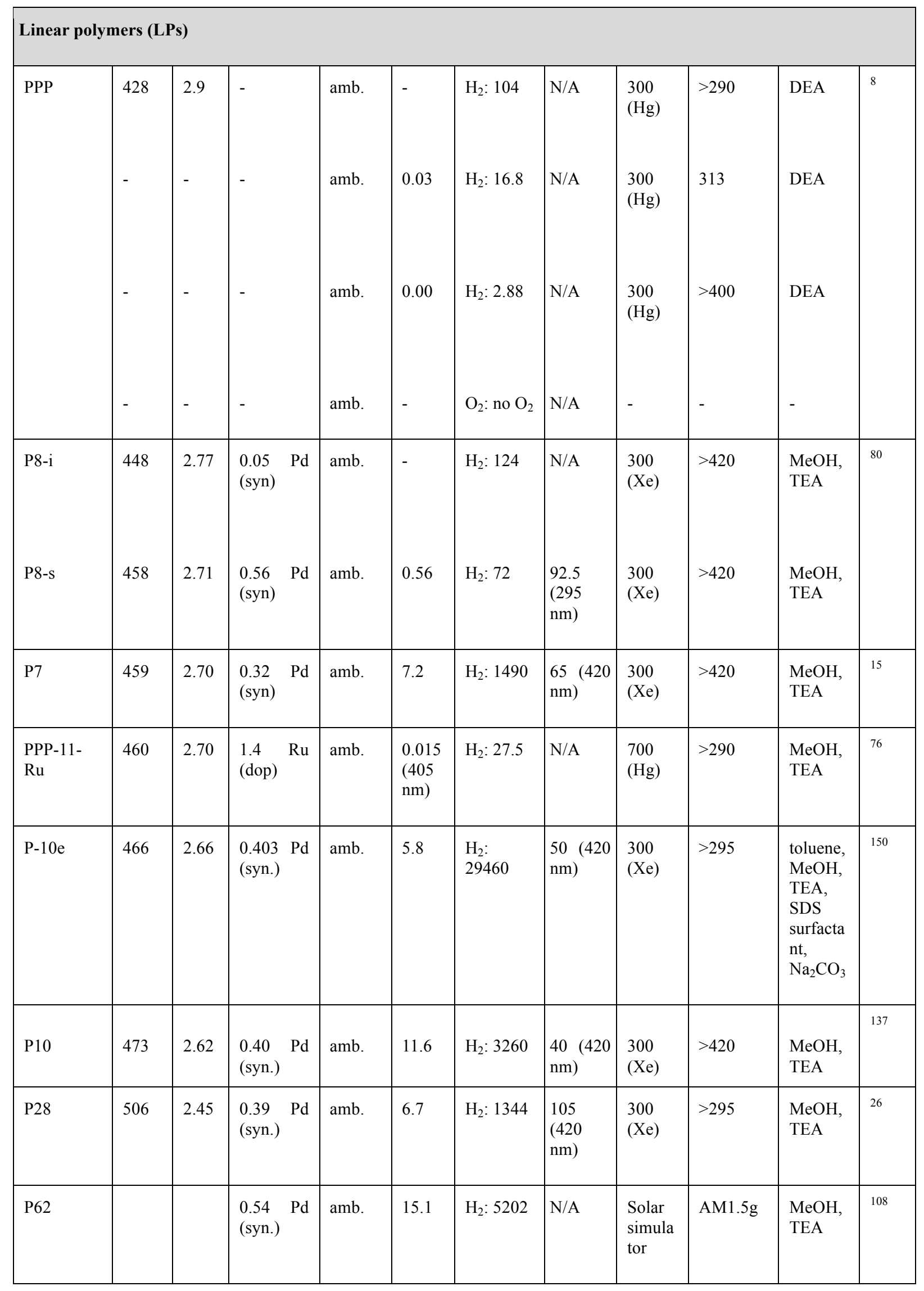




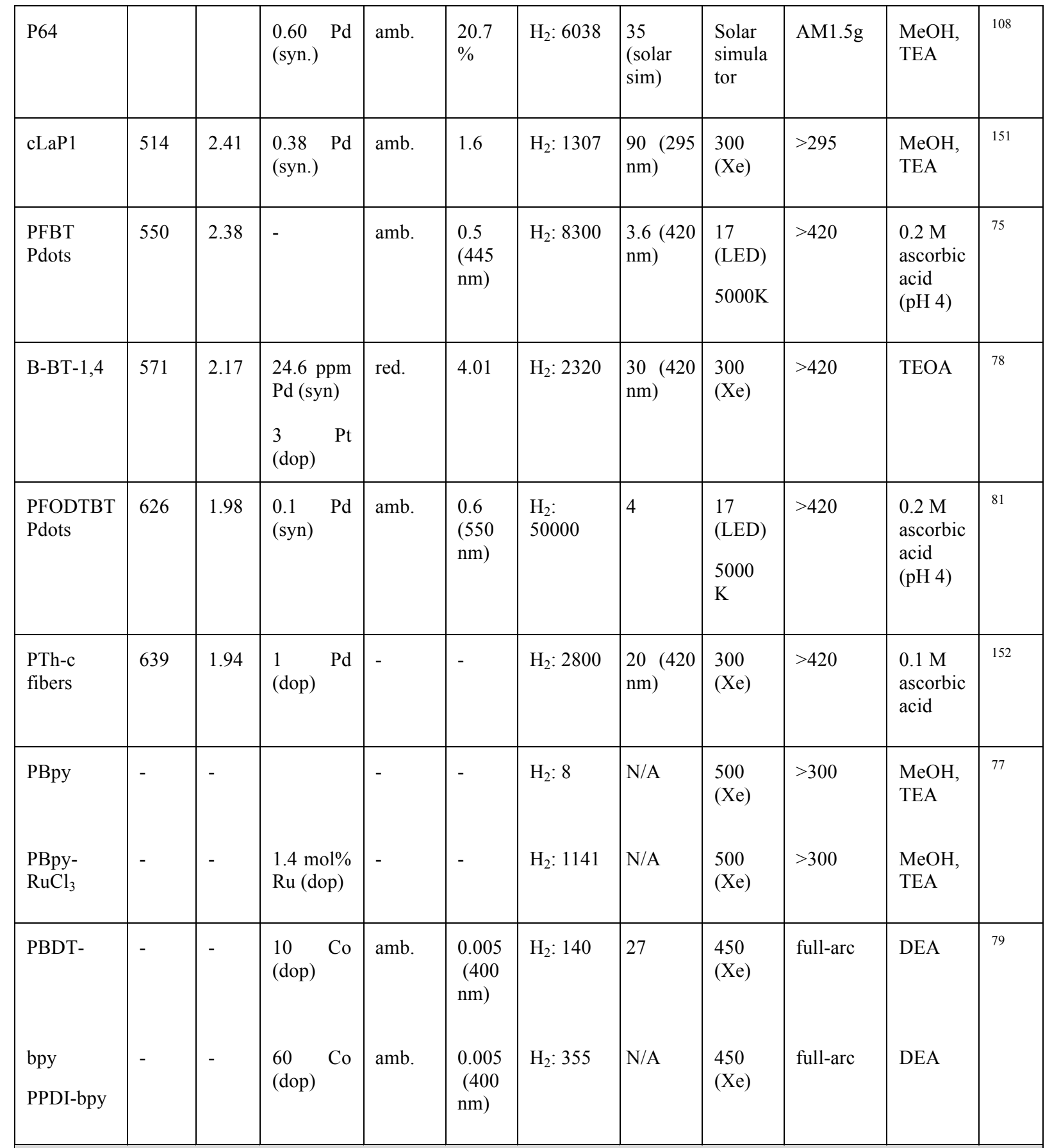

Covalent triazine frameworks (CTFs)

\begin{tabular}{|c|c|c|c|c|c|c|c|c|c|c|c|c|}
\hline PTO-300 & 370 & $3.2-$ & $\begin{array}{l}2.2 \\
\text { (dop) }\end{array}$ & $\mathrm{Pt}$ & amb. & $\begin{array}{l}5.5 \\
(400 \\
\mathrm{nm})\end{array}$ & $\mathrm{H}_{2}: 1076$ & $\begin{array}{l}100 \\
(250 \\
\mathrm{nm})\end{array}$ & $\begin{array}{l}300 \\
(\mathrm{Xe})\end{array}$ & $>420$ & $\begin{array}{l}\text { PBS } \\
(\mathrm{pH} \quad 7), \\
\text { TEOA }\end{array}$ & 83 \\
\hline $\begin{array}{l}\mathrm{Co}_{3} \mathrm{O}_{4} @ \mathrm{P} \\
\mathrm{TO}-300\end{array}$ & - & - & $\begin{array}{l}3 \\
\text { (dop) }\end{array}$ & Co & - & - & $\mathrm{O}_{2}:$ no $\mathrm{O}_{2}$ & N/A & - & - & $\mathrm{AgNO}_{3}$ & \\
\hline CTF-T1 & 422 & 2.94 & $\begin{array}{l}1 \\
\text { (dop) }\end{array}$ & $\mathrm{Pt}$ & red. & 2.4 & $\mathrm{H}_{2}: 200$ & $\begin{array}{l}20(420 \\
\mathrm{nm})\end{array}$ & - & $>420$ & TEOA & 86 \\
\hline
\end{tabular}




\begin{tabular}{|c|c|c|c|c|c|c|c|c|c|c|c|}
\hline $\begin{array}{l}\mathrm{RuO}_{2} @ \mathrm{CT} \\
\mathrm{F}-\mathrm{T} 1\end{array}$ & - & - & $\begin{array}{l}6.2 \mathrm{RuO}_{2} \\
\text { (dop) }\end{array}$ & red. & - & $\mathrm{O}_{2}: \sim 15$ & N/A & - & $>420$ & $\begin{array}{l}\mathrm{AgNO}_{3}, \\
\mathrm{La}_{2} \mathrm{O}_{3}\end{array}$ & \\
\hline PI & 428 & 2.9 & $\begin{array}{ll}1 & P t \\
\text { (dop) } & \end{array}$ & red. & - & $\mathrm{H}_{2}: 35$ & $\begin{array}{l}10(420 \\
\mathrm{nm})\end{array}$ & $\begin{array}{l}300 \\
(\mathrm{Xe})\end{array}$ & $>420$ & $\mathrm{MeOH}$ & 92 \\
\hline CTF-2 & 454 & 2.73 & $\begin{array}{ll}3 & \mathrm{Pt} \\
\text { (dop) } & \end{array}$ & amb. & 1.6 & $\mathrm{H}_{2}: 296$ & $\begin{array}{l}38 \\
\text { sun) }\end{array}$ & $\begin{array}{l}300 \\
(\mathrm{Xe})\end{array}$ & $>420$ & TEOA & 87 \\
\hline CTF-1 & 500 & 2.48 & $\begin{array}{l}2 \quad \mathrm{Pt}, \quad 3 \\
\mathrm{RuO}_{2} \\
\text { (dop) }\end{array}$ & amb. & $\begin{array}{l}\mathrm{H}_{2}: 6 \\
\mathrm{O}_{2}: \\
3.8\end{array}$ & $\begin{array}{l}\mathrm{H}_{2}: 5500 \\
\mathrm{O}_{2}: 140\end{array}$ & $\begin{array}{ll}\mathrm{H}_{2}: & 15 \\
(420 & \\
\mathrm{nm}) & \\
& \\
\mathrm{O}_{2}: & 18 \\
(420 & \\
\mathrm{nm}) & \end{array}$ & $\begin{array}{l}300 \\
(\mathrm{Xe})\end{array}$ & $>420$ & $\begin{array}{l}\mathrm{MeOH} \\
\mathrm{TEOA} \\
\mathrm{AgNO}_{3}\end{array}$ & 153 \\
\hline $\mathrm{C} 3 \mathrm{~N} 3 \mathrm{~S} 3$ & 515 & 2.4 & $\begin{array}{l}3.0 \quad \mathrm{Ru} \\
\text { (dop) }\end{array}$ & $\begin{array}{l}\text { red. } \\
\text { red. }\end{array}$ & 0.023 & $\begin{array}{l}\mathrm{H}_{2}: 8.3 \\
\mathrm{H}_{2}: 20.25\end{array}$ & $\begin{array}{l}\text { N/A } \\
\\
72 \quad(420 \\
n m)\end{array}$ & $\begin{array}{l}300 \\
(\mathrm{Xe}) \\
\\
300 \\
(\mathrm{Xe})\end{array}$ & $\begin{array}{l}>420 \\
>420\end{array}$ & $\begin{array}{l}\mathrm{Ce}^{4+} / \mathrm{Ce} \\
\mathrm{Ce}^{4+} / \mathrm{Ce}\end{array}$ & 91 \\
\hline $\begin{array}{l}\text { CTF- } \\
1 \_10 \mathrm{~min}\end{array}$ & 549 & 2.26 & Pt (dop) & deg. & $\begin{array}{l}6.4- \\
9.2 \\
(450 \\
\mathrm{nm})\end{array}$ & $\mathrm{H}_{2}: 1072$ & $\begin{array}{l}80(420 \\
\mathrm{nm})\end{array}$ & $\begin{array}{l}300 \\
(\mathrm{Xe})\end{array}$ & $>420$ & $\begin{array}{l}\text { Acetoni } \\
\text { trile, } \\
\text { buffer, } \\
\text { TEOA }\end{array}$ & 84 \\
\hline SNP-2 & 558 & 2.22 & $\begin{array}{ll}0.12 & \mathrm{Pd} \\
\text { (syn) } & \\
3 & \mathrm{Pt} \\
\text { (dop) } & \end{array}$ & amb. & - & $\mathrm{H}_{2}: 472$ & N/A & $\begin{array}{l}300 \\
(\mathrm{Xe})\end{array}$ & $>395$ & $\begin{array}{l}\text { Acetoni } \\
\text { trile, } \\
\text { TEOA }\end{array}$ & 19 \\
\hline $\mathrm{CTFS}_{10}$ & 656 & 1.89 & $\begin{array}{ll}1 & P t \\
\text { (dop) }\end{array}$ & red. & - & $\mathrm{H}_{2}: 2000$ & 20 & $\begin{array}{l}300 \\
(\mathrm{Xe})\end{array}$ & $>420$ & TEOA & 90 \\
\hline
\end{tabular}

* Values provided in this table are intended to provide an informational overview over the variety of 2 polymer photocatalysts and their properties, rather than a strictly numerical comparison of their 3 activities or quantum yields (e.g., different labs have different testing equipment). Please also refer to 4 the discussion (Linear Polymers and Polymer networks and frameworks). ${ }^{a}$ Values were 5 interconverted according to $\mathrm{E}=\mathrm{h} \times \mathrm{c} / \lambda$ and $\lambda=\mathrm{h} \times \mathrm{c} / \mathrm{E}$ with $\mathrm{h} \times \mathrm{c}=1240 \mathrm{eV} \times \mathrm{nm}$ from data reported in 6 the literature; ${ }^{b}$ Precious metal content is given according to analyses reported in the literature and 7 marked as residual content from syntheses (syn, e.g., after a Suzuki coupling reaction) or intentional 8 doping (dop, e.g., in-situ photodeposition); ${ }^{c}$ Initial pressure in the reaction vial is indicated according 9 to experimental details as ambient (amb., e.g., bubbling of nitrogen), reduced (red., e.g., evacuation of 10 reaction vessel), or degassed (deg.) when no details were provided. ${ }^{d}$ Apparent quantum yield also referred to as quantum efficiency and photonic efficiency in some of the references; ${ }^{e}$ Values were normalised to micromoles per hour and per gram $\left[\mu \mathrm{mol} \mathrm{h} \mathrm{g}^{-1}\right]$ from data reported in the literature. Oxygen evolution rates are only given (value or "no $\mathrm{O}_{2}$ ") when experiments were explicitly conducted 
1 and reported; ${ }^{f}$ Listed are sacrificial donors and further additives such as additional solvents, and 2 buffers.

3 
2 Table 3: Overview of reported conjugated microporous polymers (CMPs) and covalent organic 3 frameworks (COFs) for hydrogen and oxygen evolution.*

\begin{tabular}{|c|c|c|c|c|c|c|c|c|c|c|c|}
\hline \multirow{2}{*}{$\begin{array}{l}\text { Compo } \\
\text { und }\end{array}$} & \multicolumn{2}{|c|}{ Optical gap ${ }^{a}$} & \multirow{2}{*}{$\begin{array}{l}\text { Metal } \\
\text { cont. }^{b} \\
\text { wt\% } \%\end{array}$} & \multirow{2}{*}{$p_{c} p_{\text {initial }}$} & \multirow{2}{*}{$\begin{array}{l}\mathrm{AQY} Y^{d} \\
/ \quad \% \\
(420 \mathrm{n} \\
\mathrm{m})\end{array}$} & \multirow{2}{*}{$\begin{array}{l}\text { Gas } \\
\text { evolutio } \\
\text { n rates } \\
\mu \text { mol h}^{-1} \\
\mathbf{g}^{-1}\end{array}$} & \multirow{2}{*}{$\begin{array}{l}\text { Stabil } \\
\text { ity / h }\end{array}$} & \multicolumn{2}{|c|}{ Light source } & \multirow{2}{*}{$\begin{array}{l}\text { Conditio } \\
\text { ns }^{f}\end{array}$} & \multirow[t]{2}{*}{ Ref. } \\
\hline & $\begin{array}{l}\lambda_{\text {edge }} / \\
\mathbf{n m}\end{array}$ & $\begin{array}{l}E_{\text {gap }} \\
/ \mathrm{eV}\end{array}$ & & & & & & $\begin{array}{l}\text { Power } \\
\text { / W }\end{array}$ & $\begin{array}{l}\text { Filter } \\
\text { / nm }\end{array}$ & & \\
\hline
\end{tabular}




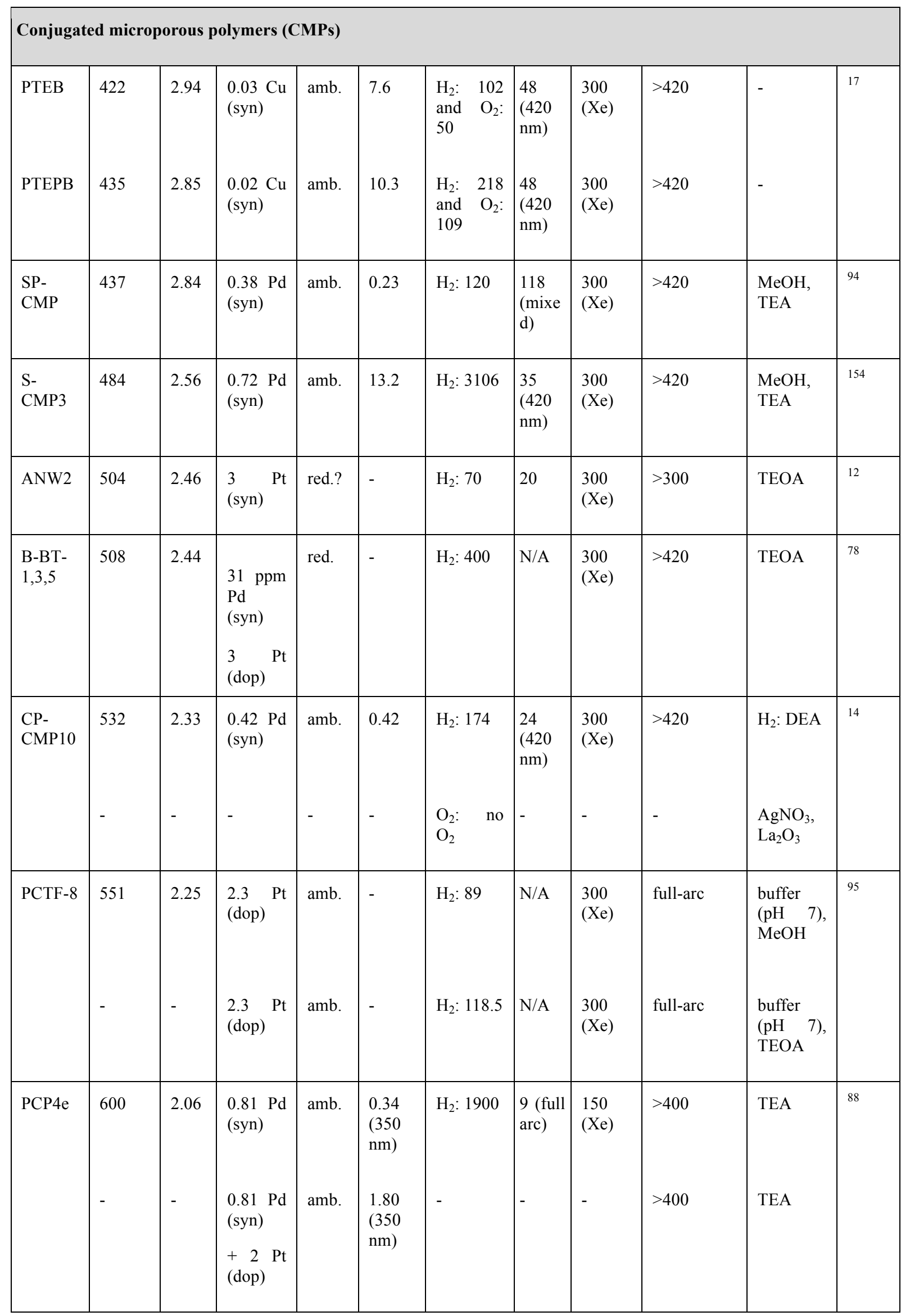




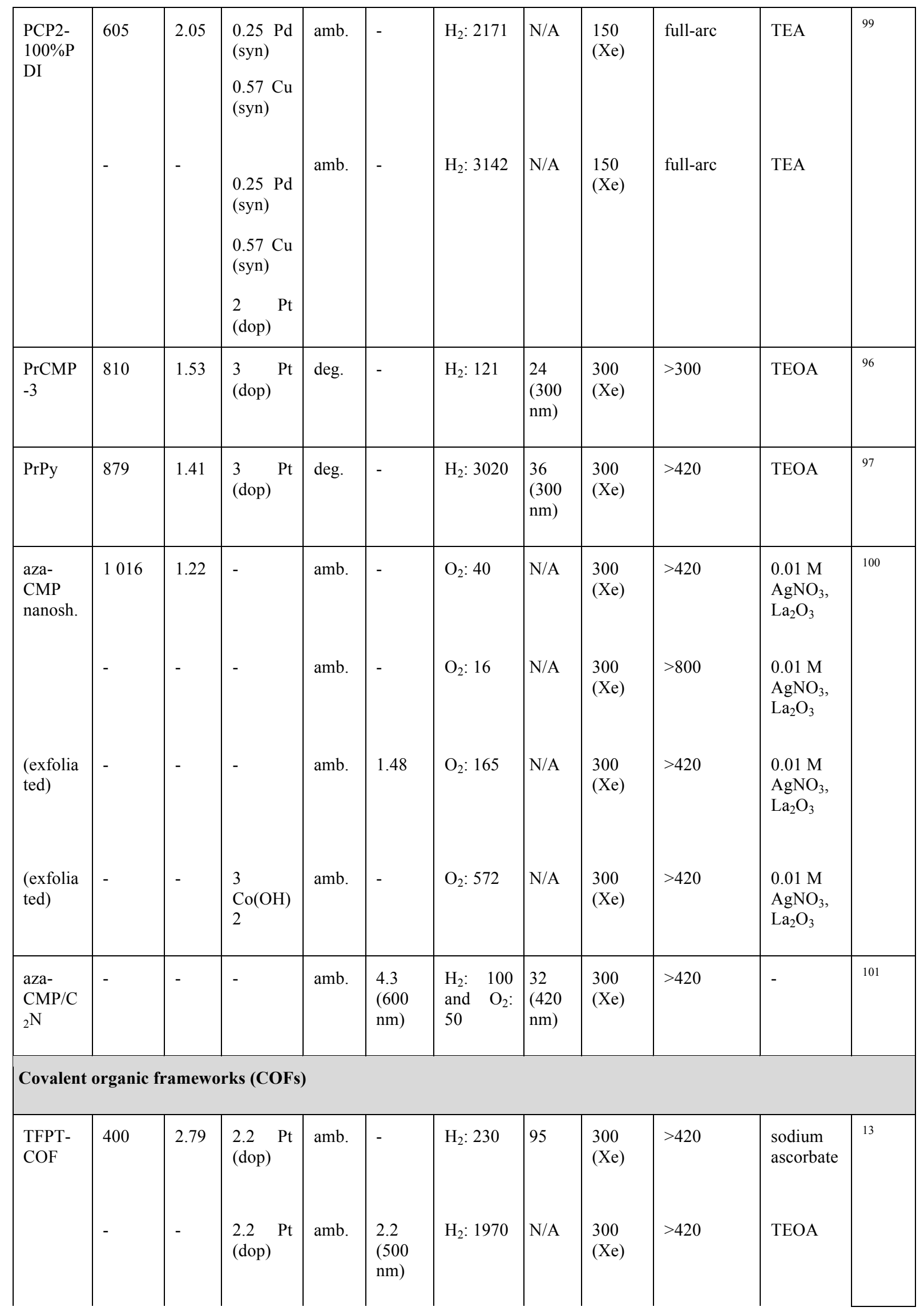




\begin{tabular}{|c|c|c|c|c|c|c|c|c|c|c|c|}
\hline $\begin{array}{l}\mathrm{IrO}_{2} @ \\
\text { TFPT- } \\
\text { COF }\end{array}$ & - & - & $\begin{array}{l}2 \\
\text { (dop) }\end{array}$ & amb. & & $\begin{array}{ll}\mathrm{O}_{2}: & \text { no } \\
\mathrm{O}_{2} & \end{array}$ & N/A & - & - & $\begin{array}{l}\text { buffer, } \\
\mathrm{Na}_{2} \mathrm{~S}_{2} \mathrm{O}_{8} \\
\text { or } \\
\mathrm{AgNO}_{3}\end{array}$ & \\
\hline $\begin{array}{l}\mathrm{N}_{3^{-}} \\
\mathrm{COF}\end{array}$ & $\begin{array}{l}465- \\
475\end{array}$ & $\begin{array}{l}2.6- \\
2.7\end{array}$ & $\begin{array}{l}0.68 \quad \mathrm{P} \\
\text { (dop) }\end{array}$ & amb. & $\begin{array}{l}0.44 \\
(450 \\
\mathrm{nm})\end{array}$ & $\mathrm{H}_{2}: 1703$ & 45 & $\begin{array}{l}300 \\
(\mathrm{Xe})\end{array}$ & $>420$ & $\begin{array}{l}\text { PBS (pH } \\
7), \text { TEOA }\end{array}$ & 104 \\
\hline $\begin{array}{l}\text { TP- } \\
\text { BDDA } \\
\text { COF }\end{array}$ & 525 & 2.31 & $\begin{array}{l}3 \text { P } \\
\text { (dop) }\end{array}$ & deg. & 1.3 & $\mathrm{H}_{2}: 324$ & 60 & $\begin{array}{l}300 \\
(\mathrm{Xe})\end{array}$ & $>395$ & TEOA & 106 \\
\hline $\begin{array}{l}\text { FS- } \\
\text { COF }\end{array}$ & 670 & 1.85 & $\begin{array}{l}8 \\
\text { (dop) }\end{array}$ & amb. & $\begin{array}{l}3.2 \\
(420 \\
\mathrm{nm})\end{array}$ & $\begin{array}{l}\mathrm{H}_{2}: \\
10100\end{array}$ & $\begin{array}{l}50 \\
(420 \\
\mathrm{nm})\end{array}$ & $\begin{array}{l}300 \\
(\mathrm{Xe})\end{array}$ & $>420$ & $\begin{array}{l}\text { ascorbic } \\
\text { acid } \\
(0.1 \mathrm{M})\end{array}$ & 107 \\
\hline $\begin{array}{l}\text { FS- } \\
\text { COF+ } \\
\text { WS5F }\end{array}$ & - & - & $\begin{array}{ll}8 & P \\
\text { (dop) }\end{array}$ & amb. & $\begin{array}{l}2.2 \\
(600 \\
\mathrm{nm})\end{array}$ & $\begin{array}{l}\mathrm{H}_{2}: \\
16300\end{array}$ & - & $\begin{array}{l}300 \\
(\mathrm{Xe})\end{array}$ & $>420$ & $\begin{array}{l}\text { ascorbic } \\
\text { acid } \\
(0.1 \mathrm{M})\end{array}$ & \\
\hline $\begin{array}{l}\mathrm{N}_{2^{-}} \\
\mathrm{COF}\end{array}$ & - & - & - & amb. & $\begin{array}{l}0.16 \\
(400 \\
\mathrm{nm})\end{array}$ & $\mathrm{H}_{2}: 782$ & 18 & $\begin{array}{l}300 \\
(\mathrm{Xe})\end{array}$ & $\begin{array}{l}100 \mathrm{~mW} \\
\mathrm{~cm}^{-2} \mathrm{AM} \\
1.5 \text { light }\end{array}$ & $\begin{array}{l}\text { acetonitri } \\
\text { le, } \\
\text { TEOA, } \\
\text { chloro(py } \\
\text { ridine)co } \\
\text { baloxime } \\
\text { co- } \\
\text { catalyst, } \\
\mathrm{dmgH}_{2} \text { at } \\
\mathrm{pH} 8\end{array}$ & 105 \\
\hline
\end{tabular}

* Values provided in this table are intended to provide an informational overview over the variety of

2 polymer photocatalysts and their properties, rather than a strictly numerical comparison of their 3 activities or quantum yields (e.g., different labs have different testing equipment). Please also refer to 4 the discussion (Polymer networks and frameworks). ${ }^{a}$ Values were interconverted according to $\mathrm{E}=$ $5 \mathrm{~h} \times \mathrm{c} / \lambda$ and $\lambda=\mathrm{h} \times \mathrm{c} / \mathrm{E}$ with $\mathrm{h} \times \mathrm{c}=1240 \mathrm{eV} \times \mathrm{nm}$ from data reported in the literature; ${ }^{b}$ Precious metal 6 content is given according to analyses reported in the literature and marked as residual content from 7 syntheses (syn, e.g., after a Suzuki coupling reaction) or intentional doping (dop, e.g. in-situ 8 photodeposition); ${ }^{c}$ Initial pressure in the reaction vial is indicated according to experimental details as 9 ambient (amb., e.g., bubbling of nitrogen), reduced (red., e.g., evacuation of reaction vessel), or 10 degassed (deg.) when no details were provided. ${ }^{d}$ Apparent quantum yield also referred to as quantum efficiency and photonic efficiency in some of the references; ${ }^{e}$ Values were normalised to micromoles per hour and per gram $\left[\mu \mathrm{mol} \mathrm{h} \mathrm{g}^{-1}\right]$ from data reported in the literature. Oxygen evolution rates are only given (value or "no $\mathrm{O}_{2}$ ") when experiments were explicitly conducted and reported; ${ }^{f}$ Listed are sacrificial donors and further additives such as additional solvents, and buffers. 

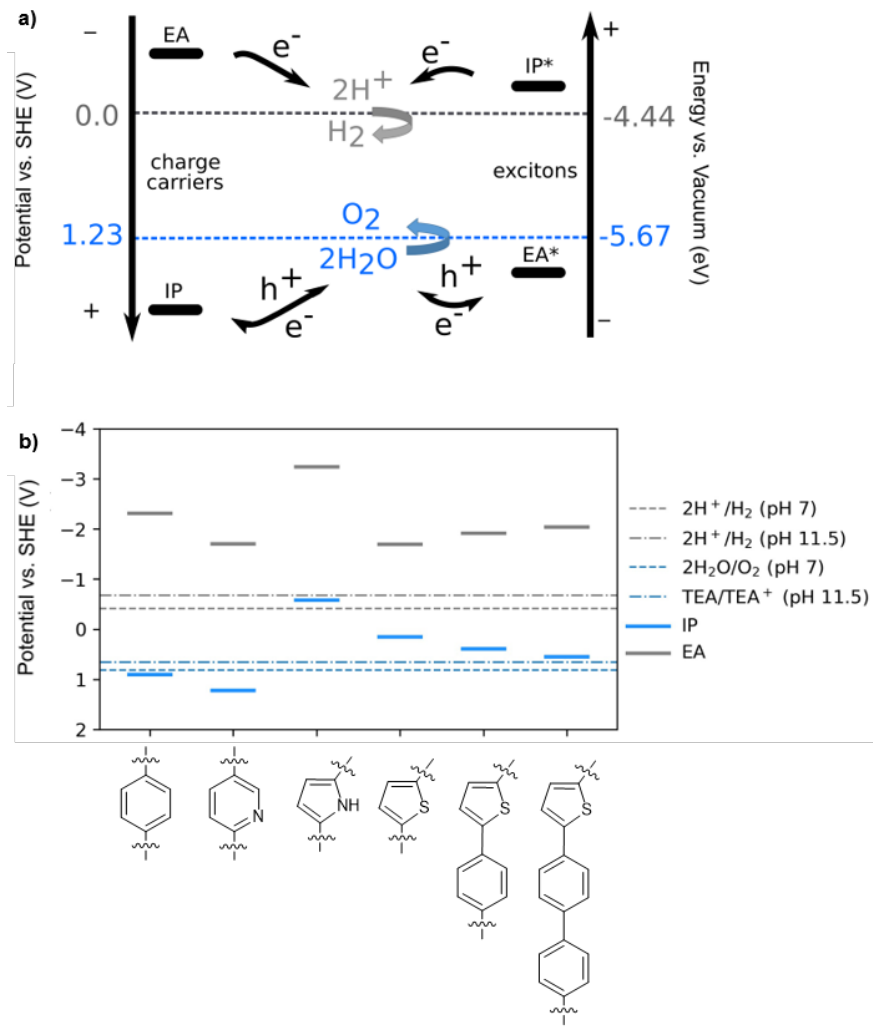

2 Fig.1 Thermodynamics of water splitting. a) Scheme illustrating how the potentials/energies of the 3 free charge carriers (IP and EA) and/or excitons (EA* and IP*) must straddle the proton reduction and 4 water oxidation potentials (black and blue broken lines, respectively) to achieve OWS. Arrows 5 indicate the direction of hole/electron transfer. b) DFT predicted IP and EA potentials for a range of 6 linear polymers. Original data taken from refs. ${ }^{21,26}$ with permission. Potentials for various solution 7 reactions are also given; proton reduction (at $\mathrm{pH} 7$ and 11.5), overall water oxidation (at $\mathrm{pH} 7$ ) and 8 one-hole oxidation of triethylamine (TEA; at pH 11.5). The potential for the overall oxidation of TEA 9 is not shown, but at $\mathrm{pH} 11.5$ (the likely $\mathrm{pH}$ of a TEA solution), it lies at the same potential as for 10 proton reduction. 

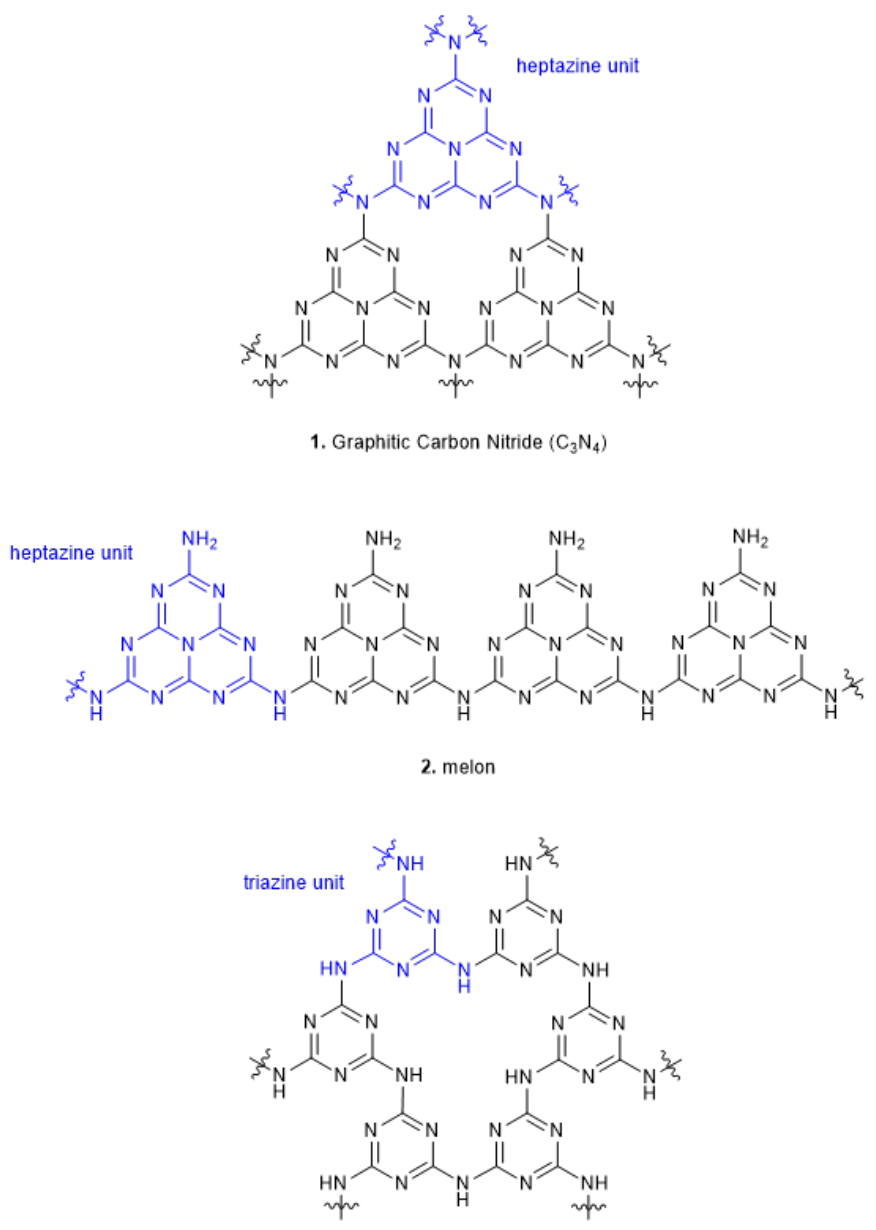

3 Fig. 2 Structures of the different (hypothetical) carbon nitride polymorphs. 1) Hypothetical 4 graphitic $\mathrm{C}_{3} \mathrm{~N}_{4}$ structure, 2) melon, the likely structure of carbon nitride materials prepared 5 experimentally through the thermal decomposition of nitrogen-containing precursors, and 3) poly 6 (triazine imide) obtained experimentally from salt melts. In each case, one heptazine/triazine unit is 7 highlighted in blue. Photocatalytically active heptazine-based carbon nitride samples $\left(\mathrm{CN}_{\mathrm{x}} \mathrm{H}_{\mathrm{y}}\right)$ appear 8 to consist of melon and are unlikely ideal $g-\mathrm{C}_{3} \mathrm{~N}_{4}$. 


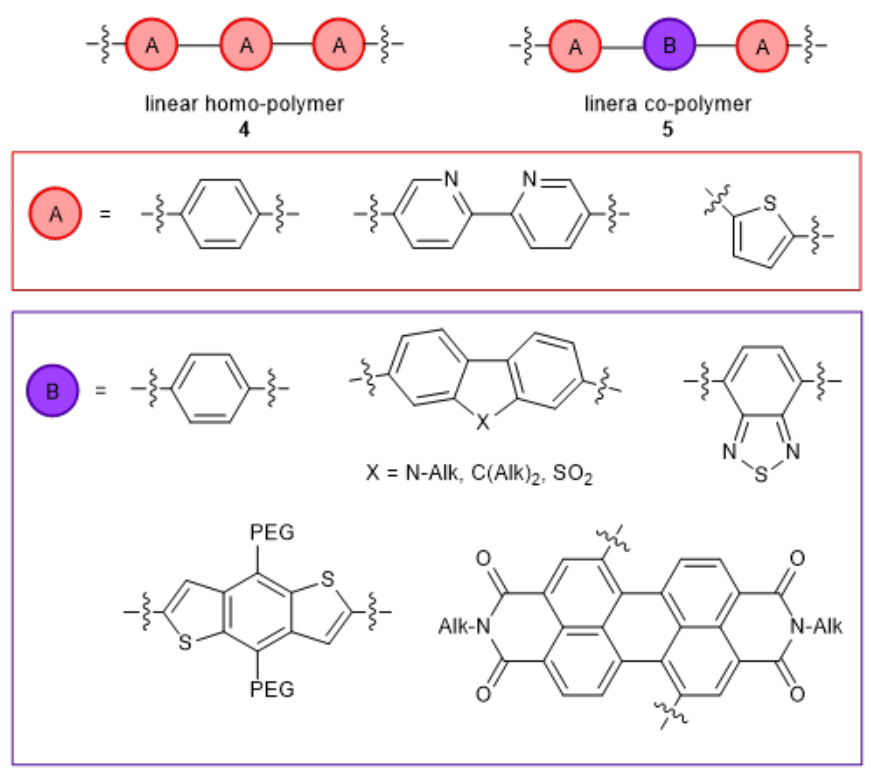

3 Fig. 3 Linear homo- and co-polymeric photocatalysts. Linear polymers typically comprise one 4 monomer (homo-polymer (4)) or two monomers (co-polymer (5)). For conjugated polymers, 5 transition metal catalysed cross-coupling reactions are often used (i.e., Suzuki-Miyaura or Stille 6 coupling). Examples of monomers are given in the figure; not all shown combinations have been 7 reported, illustrating the wide modularity of this approach. One drawback of metal-coupling 8 polymerisations is that residual noble metals can remain in the polymers, which can influence 9 photocatalytic activity; variation in this residual metal content can prevent straightforward comparison 10 between superficially similar materials, particularly for materials prepared in different laboratories 11 under slightly different reaction conditions. 

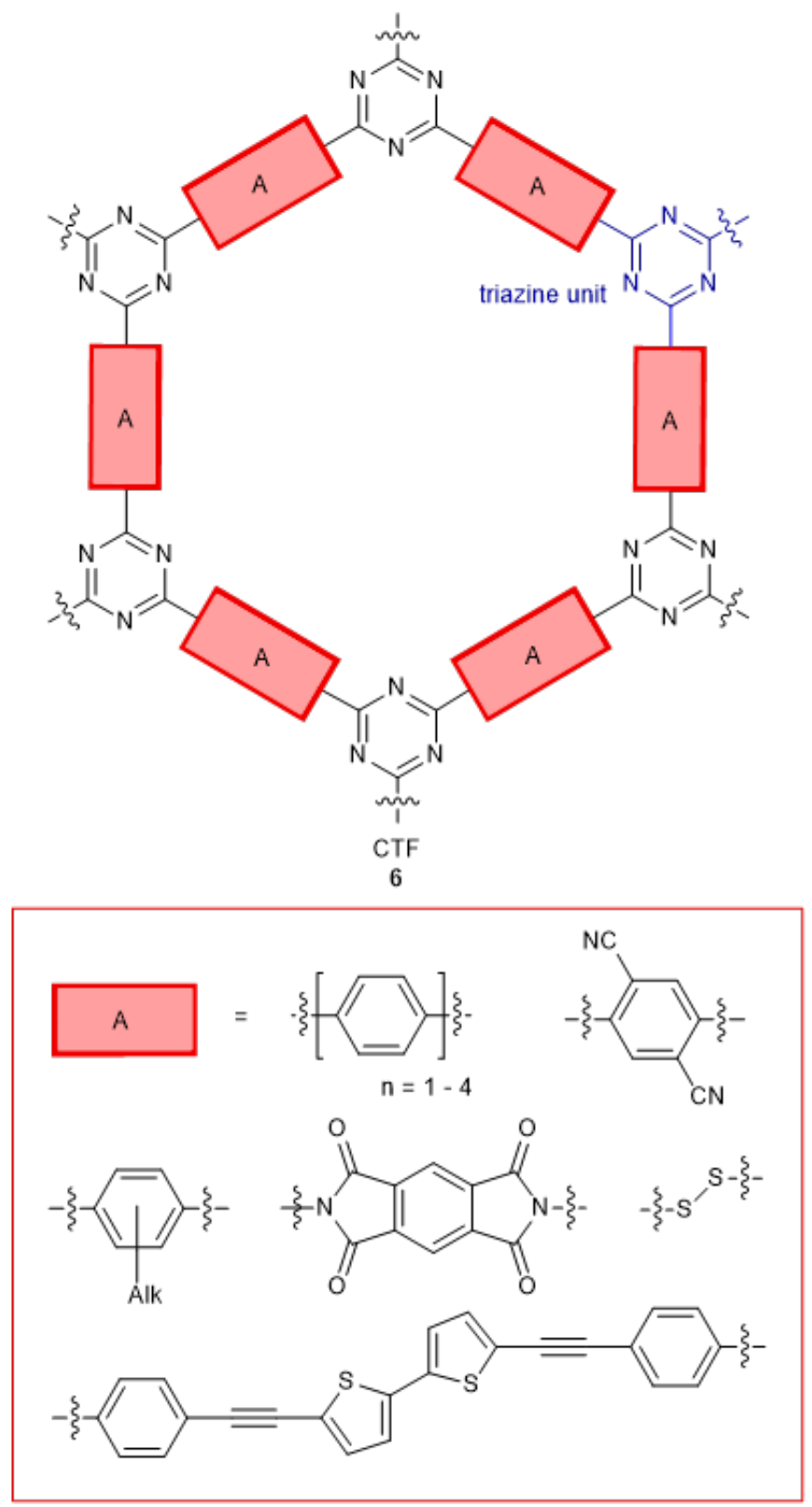

Fig. 4 Nominal structure of covalent triazine-based frameworks (CTFs). CTFs consists of a network of triazine units (highlighted in blue) that are connected via divalent bridging units (A). Most often the triazine unit is constructed in situ by a trimerisation reaction of suitable nitrile precursors via ionothermal, or super-acid catalysed approaches ${ }^{82}$. Both, the length and the nature of the bridging unit influence pore size, crystallinity, and photocatalytic activity of the final material. Due to their high nitrogen content and similarity in chemical motifs, CTFs are most closely related to $\mathrm{CN}_{\mathrm{x}} \mathrm{H}_{\mathrm{y}}$. 

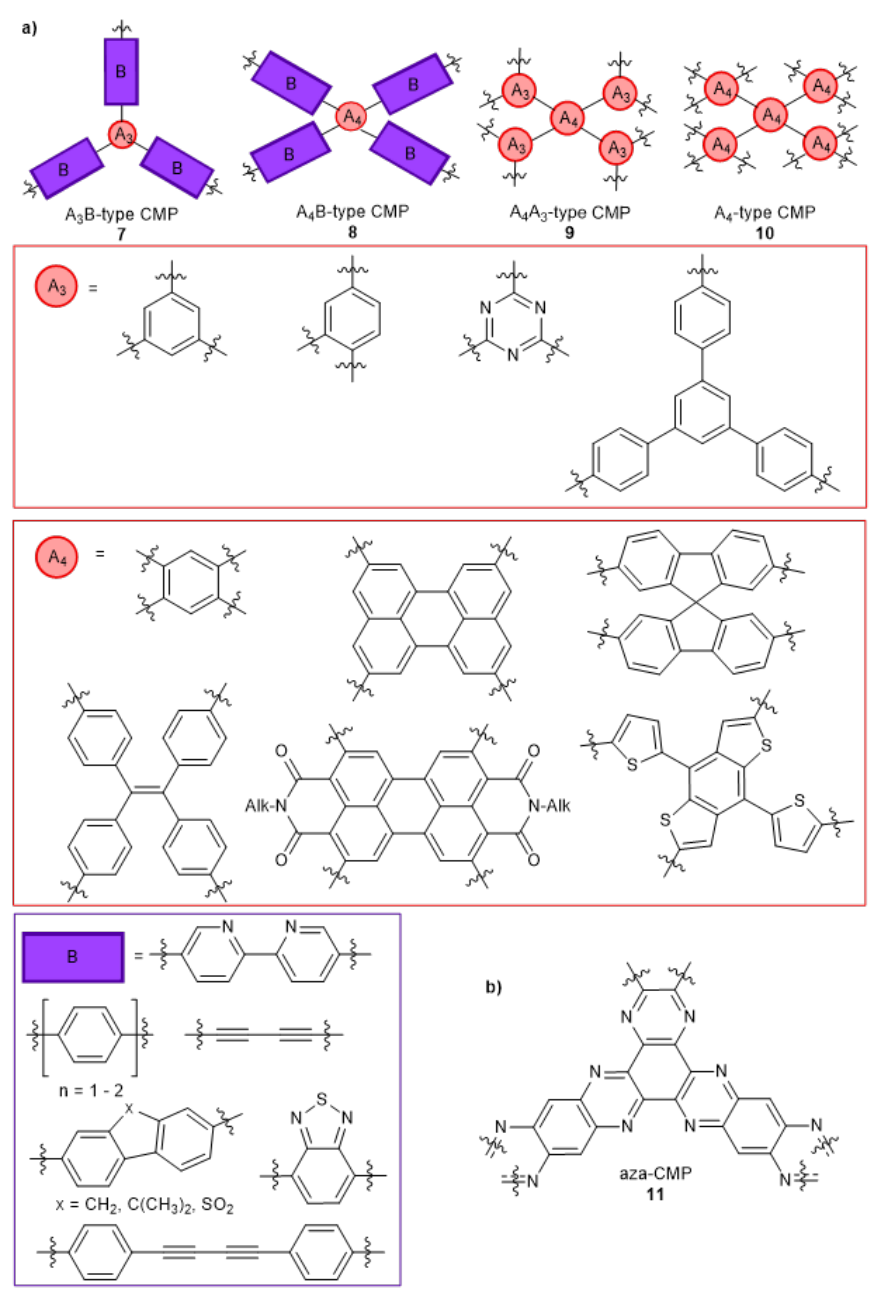

Fig. 5 Nominal structure of conjugated microporous polymer (CMP) photocatalysts. a) CMPs

3 commonly consist of a central multivalent unit $\left(\mathrm{A}_{3}\right.$ or $\left.\mathrm{A}_{4}\right)$ that is connected via di-, tri- or tetravalent 4 linkers $\left(\mathrm{B}, \mathrm{A}_{3}\right.$ or $\left.\mathrm{A}_{4}\right)$ to form a microporous network $\left(8,9\right.$ or 10 , respectively). Further, $\mathrm{A}_{3} \mathrm{~B}$-type 5 networks (7) have been reported that are structurally closely related to CTFs and in fact, encase this 6 subgroup. b) Within the CMPs, aza-CMP (11) shows unique connectivity with hexavalent central 7 units being connected via tetravalent bridges. The multi-connectivity between the structural subunits 8 creates multi-dimensional networks with a variety of pores and channels that contribute towards the 9 internal surface area (microporosity) in this class of compounds. 

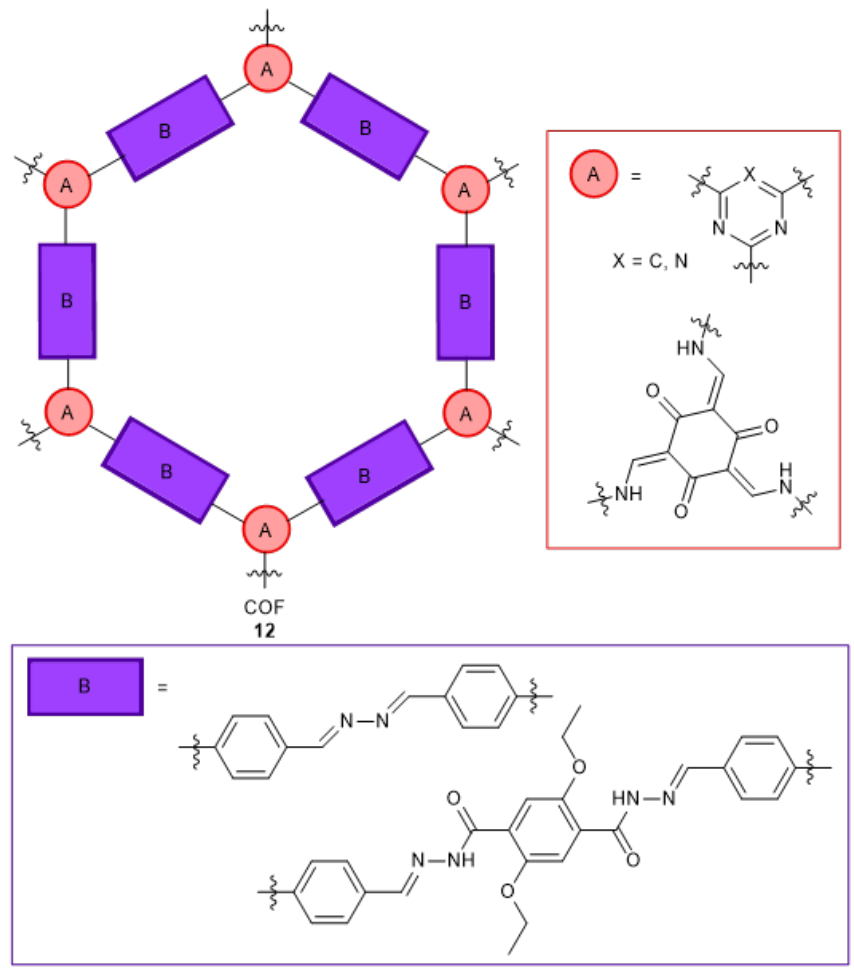

2 Fig. 6 Nominal structure of covalent organic frameworks (COFs). To date, the majority of 3 crystalline conjugated COFs consist of trivalent central units connected via divalent bridging units, 4 rather like CTFs and $\mathrm{A}_{3} \mathrm{~B}$-type CMPs. In contrast to CTFs and CMPs, they tend not to possess any 5 extended $\pi$-conjugation in the plane of the COF layers due to the synthetic necessity of reversible 6 linker bond formation; this has most often been achieved via imine-bond formation. While 7 reversibility during synthesis benefits the formation of highly crystalline materials, it may be a 8 drawback for photocatalytic applications due to the vulnerability of these linkages under 9 photocatalytic reaction conditions. 
21 Pinaud, B. A. et al. Technical and economic feasibility of centralized facilities for solar

2 Zhang, J. \& Wang, X. Solar Water Splitting at $\lambda=600 \mathrm{~nm}$ : A Step Closer to Sustainable Hydrogen Production. Angew. Chem. Int. Ed. 54, 7230-7232, doi:doi:10.1002/anie.201502659 (2015).

6 Peng, G., Volokh, M., Tzadikov, J., Sun, J. \& Shalom, M. Carbon Nitride/Reduced Graphene Oxide Film with Enhanced Electron Diffusion Length: An Efficient Photo-Electrochemical Cell for Hydrogen Generation. Adv. Energy Mater. 8, 1800566, doi:10.1002/aenm.201800566 (2018).

$7 \quad \mathrm{Xu}$, J. et al. Color-Tunable Photoluminescence and NIR Electroluminescence in Carbon Nitride Thin Films and Light-Emitting Diodes. Adv. Opt. Mater. 3, 913-917, doi:10.1002/adom.201500019 (2015).

8 Yanagida, S., Kabumoto, A., Mizumoto, K., Pac, C. \& Yoshino, K. Poly (p-phenylene)-catalysed photoreduction of water to hydrogen. J. Chem. Soc., Chem. Commun., 474-475, doi:10.1039/C39850000474 (1985).

9 Matsuoka, S. et al. Photocatalysis of oligo(p-phenylenes): photoreductive production of hydrogen and ethanol in aqueous triethylamine. J. Phys. Chem. 95, 5802-5808, doi:10.1021/j100168a018 (1991).

10 Wang, X. et al. A metal-free polymeric photocatalyst for hydrogen production from water under visible light. Nat. Mater. 8, 76-80 (2009).

11 Kuhn, P., Antonietti, M. \& Thomas, A. Porous, Covalent Triazine-Based Frameworks Prepared by lonothermal Synthesis. Angew. Chem. Int. Ed. 47, 3450-3453, doi:doi:10.1002/anie.200705710 (2008).

12 Schwab, M. G. et al. Photocatalytic hydrogen evolution through fully conjugated poly(azomethine) networks. Chem. Commun. 46, 8932-8934, doi:10.1039/C0CC04057F (2010).

13 Stegbauer, L., Schwinghammer, K. \& Lotsch, B. V. A hydrazone-based covalent organic framework for photocatalytic hydrogen production. Chemical Science 5, 2789-2793, doi:10.1039/c4sc00016a (2014).

14 Sprick, R. S. et al. Tunable Organic Photocatalysts for Visible-Light-Driven Hydrogen Evolution. J. Am. Chem. Soc. 137, 3265-3270, doi:10.1021/ja511552k (2015). 
15 Sprick, R. S. et al. Visible-Light-Driven Hydrogen Evolution Using Planarized Conjugated Polymer Photocatalysts. Angew. Chem. Int. Ed. 55, 1792-1796, doi:doi:10.1002/anie.201510542 (2016). Liu, J. et al. Metal-free efficient photocatalyst for stable visible water splitting via a twoelectron pathway. Science 347, 970-974, doi:10.1126/science.aaa3145 (2015). Ruan, Q. et al. A Nanojunction Polymer Photoelectrode for Efficient Charge Transport and Separation. Angew. Chem. Int. Ed. 56, 8221-8225, doi:doi:10.1002/anie.201703372 (2017).

Zhang, G., Lan, Z.-A., Lin, L., Lin, S. \& Wang, X. Overall water splitting by Pt/g-C3N4 photocatalysts without using sacrificial agents. Chem. Sci. 7, 3062-3066, doi:10.1039/C5SC04572J (2016). Schwarz, D. et al. Tailored Band Gaps in Sulfur- and Nitrogen-Containing Porous DonorAcceptor Polymers. Chem. Eur. J. 23, 13023-13027, doi:10.1002/chem.201703332 (2017). Kosco, J. et al. The Effect of Residual Palladium Catalyst Contamination on the Photocatalytic Hydrogen Evolution Activity of Conjugated Polymers. Adv. Energy Mater. 0, 1802181, doi:doi:10.1002/aenm.201802181 (2018).

21 Sprick, R. S. et al. Maximising the hydrogen evolution activity in organic photocatalysts by co-polymerisation. J. Mater. Chem. A 6, 11994-12003, doi:10.1039/C8TA04186E (2018). Roncali, J. Synthetic Principles for Bandgap Control in Linear pi-Conjugated Systems. Chem. Rev. 97, 173-206, doi:10.1021/cr950257t (1997).

23
Guiglion, P., Butchosa, C. \& Zwijnenburg, M. A. Polymer Photocatalysts for Water Splitting: Insights from Computational Modeling. Macromol. Chem. Phys. 217, 344-353, doi:10.1002/macp.201500432 (2016). Tamai, Y., Ohkita, H., Benten, H. \& Ito, S. Exciton Diffusion in Conjugated Polymers: From Fundamental Understanding to Improvement in Photovoltaic Conversion Efficiency. J. Phys. Chem. Lett. 6, 3417-3428, doi:10.1021/acs.jpclett.5b01147 (2015).

25 Clarke, T. M. \& Durrant, J. R. Charge Photogeneration in Organic Solar Cells. Chem. Rev. 110, 6736-6767, doi:10.1021/cr900271s (2010).

26 Sprick, R. S. et al. Nitrogen Containing Linear Poly(phenylene) Derivatives for Photo-catalytic Hydrogen Evolution from Water. Chem. Mater. 30, 5733-5742, doi:10.1021/acs.chemmater.8b02501 (2018).

27 Reiner Sebastian, S., Yang, B., Catherine M., A., Duncan J., W. \& Andrew I., C. Photocatalytic Hydrogen Evolution from Water Using Heterocyclic Conjugated Microporous Polymers: Porous or Non-Porous? , (2018).

28 Wang, Y. et al. Linker-controlled polymeric photocatalyst for highly efficient hydrogen evolution from water. Energy Environ. Sci. 10, 1643-1651, doi:10.1039/C7EE01109A (2017).

29 Liu, G. et al. Nature-Inspired Environmental "Phosphorylation" Boosts Photocatalytic H2 Production over Carbon Nitride Nanosheets under Visible-Light Irradiation. Angew. Chem. Int. Ed. 54, 13561-13565, doi:10.1002/anie.201505802 (2015).

30 Zhang, G. et al. Tailoring the Grain Boundary Chemistry of Polymeric Carbon Nitride for Enhanced Solar Hydrogen Production and CO2 Reduction. Angew. Chem. Int. Ed. 131, 34713475, doi:10.1002/ange.201811938 (2019). 
31 Botari, T., Huhn, W. P., Lau, V. W.-h., Lotsch, B. V. \& Blum, V. Thermodynamic Equilibria in Carbon Nitride Photocatalyst Materials and Conditions for the Existence of Graphitic Carbon Nitride g-C3N4. Chem. Mater. 29, 4445-4453, doi:10.1021/acs.chemmater.7b00965 (2017). Jorge, A. B. et al. $\mathrm{H} 2$ and $\mathrm{O} 2$ Evolution from Water Half-Splitting Reactions by Graphitic Carbon Nitride Materials. J. Phys. Chem. C 117, 7178-7185, doi:10.1021/jp4009338 (2013).

Lotsch, B. V. et al. Unmasking Melon by a Complementary Approach Employing Electron Diffraction, Solid-State NMR Spectroscopy, and Theoretical Calculations-Structural Characterization of a Carbon Nitride Polymer. Chem. Eur. J. 13, 4969-4980, doi:10.1002/chem.200601759 (2007). Liebig, J. Uber einige Stickstoff - Verbindungen. Annalen der Pharmacie 10, 1-47, doi:10.1002/jlac.18340100102 (1834).

35 Wirnhier, E. et al. Poly(triazine imide) with intercalation of lithium and chloride ions [(C3N3)2(NH(x)Li(1-x))3LiCl]: a crystalline 2D carbon nitride network. Chem. Eur. J. 17, 32133221, doi:10.1002/chem.201002462 (2011).

36 Martin, D. J. et al. Highly Efficient Photocatalytic H2 Evolution from Water using Visible Light and Structure-Controlled Graphitic Carbon Nitride. Angew. Chem. Int. Ed. 53, 9240-9245 (2014).

37 Zhang, G. et al. Ionothermal Synthesis of Triazine-Heptazine-Based Copolymers with Apparent Quantum Yields of $60 \%$ at $420 \mathrm{~nm}$ for Solar Hydrogen Production from "Sea Water". Angew. Chem. Int. Ed. 57, 9372-9376, doi:doi:10.1002/anie.201804702 (2018). Zhou, Z., Zhang, Y., Shen, Y., Liu, S. \& Zhang, Y. Molecular engineering of polymeric carbon nitride: advancing applications from photocatalysis to biosensing and more. Chem. Soc. Rev. 47, 2298-2321, doi:10.1039/C7CS00840F (2018).

39 Yang, S. et al. Exfoliated Graphitic Carbon Nitride Nanosheets as Efficient Catalysts for Hydrogen Evolution Under Visible Light. Adv. Mater. 25, 2452-2456, doi:10.1002/adma.201204453 (2013).

40 Yang, Z., Zhang, Y. \& Schnepp, Z. Soft and hard templating of graphitic carbon nitride. J. Mater. Chem. A 3, 14081-14092, doi:10.1039/C5TA02156A (2015).

41 Bhunia, M. K., Yamauchi, K. \& Takanabe, K. Harvesting Solar Light with Crystalline Carbon Nitrides for Efficient Photocatalytic Hydrogen Evolution. Angew. Chem. Int. Ed. 126, 1118111185, doi:10.1002/ange.201405161 (2014).

42 Liu, G. et al. In Situ Bond Modulation of Graphitic Carbon Nitride to Construct p-n Homojunctions for Enhanced Photocatalytic Hydrogen Production. Adv. Funct. Mater. 26, 6822-6829, doi:10.1002/adfm.201602779 (2016).

43 Chen, Z. et al. Gradual carbon doping of graphitic carbon nitride towards metal-free visible light photocatalytic hydrogen evolution. J. Mater. Chem. A 6, 15310-15319, doi:10.1039/C8TA03303J (2018).

44 Barrio, J., Lin, L., Wang, X. \& Shalom, M. Design of a Unique Energy-Band Structure and Morphology in a Carbon Nitride Photocatalyst for Improved Charge Separation and Hydrogen Production. ACS Sustain. Chem. Eng. 6, 519-530, doi:10.1021/acssuschemeng.7b02807 (2018). 
45 Fan, Q., Liu, J., Yu, Y., Zuo, S. \& Li, B. A simple fabrication for sulfur doped graphitic carbon nitride porous rods with excellent photocatalytic activity degrading RhB dye. Appl. Surf. Sci. 391, 360-368, doi:https://doi.org/10.1016/j.apsusc.2016.04.055 (2017).

46 Liao, Y. et al. Tailoring the Morphology of g-C3N4 by Self-Assembly towards High Photocatalytic Performance. ChemCatChem 6, 3419-3425, doi:10.1002/cctc.201402654 (2014).

47 Jun, Y.-S. et al. From Melamine-Cyanuric Acid Supramolecular Aggregates to Carbon Nitride Hollow Spheres. Adv. Funct. Mater. 23, 3661-3667, doi:10.1002/adfm.201203732 (2013).

48 Wan, S., Ou, M., Zhong, Q., Zhang, S. \& Cai, W. Supramolecular Synthesis of Multifunctional Holey Carbon Nitride Nanosheet with High-Efficiency Photocatalytic Performance. Adv. Opt. Mater. 5, 1700536, doi:10.1002/adom.201700536 (2017).

49 Shi, L. et al. In site acid template induced facile synthesis of porous graphitic carbon nitride with enhanced visible-light photocatalytic activity. Catal. Commun. 89, 129-132, doi:https://doi.org/10.1016/j.catcom.2016.10.020 (2017).

50 Barrio, J., Grafmüller, A., Tzadikov, J. \& Shalom, M. Halogen-hydrogen bonds: A general synthetic approach for highly photoactive carbon nitride with tunable properties. Appl. Catal., B 237, 681-688, doi:https://doi.org/10.1016/j.apcatb.2018.06.043 (2018).

51 Xie, M., Wei, W., Jiang, Z., Xu, Y. \& Xie, J. Carbon nitride nanowires/nanofibers: A novel template-free synthesis from a cyanuric chloride-melamine precursor towards enhanced adsorption and visible-light photocatalytic performance. Ceram. Int. 42, 4158-4170, doi:https://doi.org/10.1016/j.ceramint.2015.11.089 (2016).

52 Hong, Y. et al. Precisely tunable thickness of graphitic carbon nitride nanosheets for visiblelight-driven photocatalytic hydrogen evolution. Nanoscale 9, 14103-14110, doi:10.1039/C7NR05155G (2017).

53 Barrio, J. et al. Unprecedented Centimeter-Long Carbon Nitride Needles: Synthesis, Characterization and Applications. Small 14, 1800633, doi:10.1002/smll.201800633 (2018).

54 Bai, J., Han, Q., Cheng, Z. \& Qu, L. Wall-Mesoporous Graphitic Carbon Nitride Nanotubes for Efficient Photocatalytic Hydrogen Evolution. Chem. Asian J. 13, 3160-3164, doi:10.1002/asia.201801209 (2018).

55 Wang, J. et al. Direct Synthesis of Porous Nanorod-Type Graphitic Carbon Nitride/CuO Composite from Cu-Melamine Supramolecular Framework towards Enhanced Photocatalytic Performance. Chem. Asian J. 10, 1276-1280, doi:10.1002/asia.201500131 (2015).

56 Lau, V. W.-h. et al. Rational design of carbon nitride photocatalysts by identification of cyanamide defects as catalytically relevant sites. Nat. Comm. 7, doi:10.1038/ncomms12165 (2016). Lau, V. W.-h. et al. Urea-Modified Carbon Nitrides: Enhancing Photocatalytic Hydrogen Evolution by Rational Defect Engineering. Adv. Energy Mater., 1602251-n/a, doi:10.1002/aenm.201602251 (2017). Lin, L., Ou, H., Zhang, Y. \& Wang, X. Tri-s-triazine-Based Crystalline Graphitic Carbon Nitrides for Highly Efficient Hydrogen Evolution Photocatalysis. ACS Catal. 6, 3921-3931, doi:10.1021/acscatal.6b00922 (2016).

Wang, L. et al. Conjugated Microporous Polymer Nanosheets for Overall Water Splitting Using Visible Light. Adv. Mater. 29, 1702428, doi:doi:10.1002/adma.201702428 (2017). 
Yu, H. et al. Alkali-Assisted Synthesis of Nitrogen Deficient Graphitic Carbon Nitride with Tunable Band Structures for Efficient Visible-Light-Driven Hydrogen Evolution. Adv. Mater. 29, 1605148, doi:doi:10.1002/adma.201605148 (2017).

61 Guo, S. et al. Phosphorus-Doped Carbon Nitride Tubes with a Layered Micro-nanostructure for Enhanced Visible-Light Photocatalytic Hydrogen Evolution. Angew. Chem. Int. Ed. 55, 1830-1834, doi:10.1002/anie.201508505 (2016). Fang, J., Fan, H., Li, M. \& Long, C. Nitrogen self-doped graphitic carbon nitride as efficient visible light photocatalyst for hydrogen evolution. J. Mater. Chem. A 3, 13819-13826, doi:10.1039/C5TA02257F (2015).

$63 \mathrm{Li}, \mathrm{J}$. et al. A facile approach to synthesize novel oxygen-doped g-C3N4 with superior visiblelight photoreactivity. Chem. Commun. 48, 12017-12019, doi:10.1039/C2CC35862J (2012).

64 Wang, Y., Li, H., Yao, J., Wang, X. \& Antonietti, M. Synthesis of boron doped polymeric carbon nitride solids and their use as metal-free catalysts for aliphatic $\mathrm{C}-\mathrm{H}$ bond oxidation. Chem. Sci. 2, 446-450, doi:10.1039/COSC00475H (2011).

65 Wang, Y. et al. Excellent Visible-Light Photocatalysis of Fluorinated Polymeric Carbon Nitride Solids. Chem. Mater. 22, 5119-5121, doi:10.1021/cm1019102 (2010).

66 Zhang, J. et al. Synthesis of a Carbon Nitride Structure for Visible-Light Catalysis by Copolymerization. Angew. Chem. Int. Ed. 49, 441-444, doi:10.1002/anie.200903886 (2010).

67 Zhang, J. et al. Co-Monomer Control of Carbon Nitride Semiconductors to Optimize Hydrogen Evolution with Visible Light. Angew. Chem. Int. Ed. 124, 3237-3241, doi:10.1002/ange.201106656 (2012).

68 Barrio, J. \& Shalom, M. Rational Design of Carbon Nitride Materials by Supramolecular Preorganization of Monomers. ChemCatChem 10, 5573-5586, doi:10.1002/cctc.201801410 (2018).

69 Wang, Y. et al. Bandgap Engineering of Organic Semiconductors for Highly Efficient Photocatalytic Water Splitting. Adv. Energy Mater. 8, 1801084, doi:10.1002/aenm.201801084 (2018).

70 Li, M. et al. Graphene with Atomic-Level In-Plane Decoration of h-BN Domains for Efficient Photocatalysis. Chem. Mater. 29, 2769-2776, doi:10.1021/acs.chemmater.6b04622 (2017).

71 Zhang, G., Zhang, J., Zhang, M. \& Wang, X. Polycondensation of thiourea into carbon nitride semiconductors as visible light photocatalysts. J. Mater. Chem. 22, 8083-8091, doi:10.1039/C2JM00097K (2012).

72 Zhang, G., Huang, C. \& Wang, X. Dispersing Molecular Cobalt in Graphitic Carbon Nitride Frameworks for Photocatalytic Water Oxidation. Small 11, 1215-1221, doi:10.1002/smll.201402636 (2015).

73 Zhao, G., Huang, X., Fina, F., Zhang, G. \& Irvine, J. T. Facile structure design based on C 3 N 4 for mediator-free Z-scheme water splitting under visible light. Catal. Sci. Technol. 5, 34163422 (2015).

74 Sui, Y., Liu, J., Zhang, Y., Tian, X. \& Chen, W. Dispersed conductive polymer nanoparticles on graphitic carbon nitride for enhanced solar-driven hydrogen evolution from pure water. Nanoscale 5, 9150-9155, doi:10.1039/C3NR02413J (2013).

Wang, L. et al. Organic Polymer Dots as Photocatalysts for Visible Light-Driven Hydrogen Generation. Angew. Chem. Int. Ed. 55, 12306-12310, doi:10.1002/anie.201607018 (2016). 
76 Shibata, T. et al. Novel visible-light-driven photocatalyst. Poly (p-phenylene)-catalyzed photoreductions of water, carbonyl compounds, and olefins. J. Phys. Chem. 94, 2068-2076, doi:10.1021/j100368a063 (1990).

77 Yamamoto, T., Yoneda, Y. \& Maruyama, T. Ruthenium and nickel complexes of a $\pi-$ conjugated electrically conducting polymer chelate ligand, poly(2,2'-bipyridine-5,5'-diyl), and their chemical and catalytic reactivity. J. Chem. Soc., Chem. Commun. 0, 1652-1654, doi:10.1039/c39920001652 (1992).

78 Yang, C. et al. Molecular Engineering of Conjugated Polybenzothiadiazoles for Enhanced Hydrogen Production by Photosynthesis. Angew. Chem. Int. Ed. 55, 9202-9206, doi:10.1002/anie.201603532 (2016).

79 Li, L. et al. Photocatalysts Based on Cobalt-Chelating Conjugated Polymers for Hydrogen Evolution from Water. Chem. Mater. 28, 5394-5399, doi:10.1021/acs.chemmater.6b01477 (2016).

80 Woods, D. J., Sprick, R. S., Smith, C. L., Cowan, A. J. \& Cooper, A. I. A Solution-Processable Polymer Photocatalyst for Hydrogen Evolution from Water. Adv. Energy Mater. 7, 1700479n/a, doi:10.1002/aenm.201700479 (2017).

81 Pati, P. B. et al. An experimental and theoretical study of an efficient polymer nanophotocatalyst for hydrogen evolution. Energy Environ. Sci. 10, 1372-1376, doi:10.1039/C7EE00751E (2017).

82 Liu, M., Guo, L., Jin, S. \& Tan, B. Covalent triazine frameworks: synthesis and applications. J. Mater. Chem. A 7, 5153-5172, doi:10.1039/C8TA12442F (2019).

83 Schwinghammer, K., Hug, S., Mesch, M. B., Senker, J. \& Lotsch, B. V. Phenyl-triazine oligomers for light-driven hydrogen evolution. Energy Environ. Sci. 8, 3345-3353, doi:10.1039/C5EE02574E (2015).

84 Kuecken, S. et al. Fast tuning of covalent triazine frameworks for photocatalytic hydrogen evolution. Chem. Commun. 53, 5854-5857, doi:10.1039/C7CC01827D (2017).

85 Kuhn, P., Thomas, A. \& Antonietti, M. Toward Tailorable Porous Organic Polymer Networks: A High-Temperature Dynamic Polymerization Scheme Based on Aromatic Nitriles. Macromolecules 42, 319-326, doi:10.1021/ma802322j (2009).

$86 \mathrm{Bi}$, J. et al. Covalent Triazine-Based Frameworks as Visible Light Photocatalysts for the Splitting of Water. Macromol. Rapid Commun. 36, 1799-1805, doi:10.1002/marc. 201500270 (2015).

87 Meier, C. B. et al. Structure-property relationships for covalent triazine-based frameworks: The effect of spacer length on photocatalytic hydrogen evolution from water. Polymer 126, 283-290, doi:10.1016/j.polymer.2017.04.017 (2017).

88 Li, L. et al. Rational Design of Porous Conjugated Polymers and Roles of Residual Palladium for Photocatalytic Hydrogen Production. J. Am. Chem. Soc. 138, 7681-7686, doi:10.1021/jacs.6b03472 (2016).

89 Maeda, K. et al. Photocatalytic Activities of Graphitic Carbon Nitride Powder for Water Reduction and Oxidation under Visible Light. J. Phys. Chem. C 113, 4940-4947, doi:10.1021/jp809119m (2009). 
$90 \mathrm{Li}$, L. et al. Sulfur-doped covalent triazine-based frameworks for enhanced photocatalytic hydrogen evolution from water under visible light. J. Mater. Chem. A 4, 12402-12406, doi:10.1039/C6TA04711D (2016).

91 Zhang, Z. et al. Organic semiconductor for artificial photosynthesis: water splitting into hydrogen by a bioinspired C3N3S3polymer under visible light irradiation. Chem. Sci. 2, 18261830, doi:10.1039/c1sc00257k (2011).

92 Chu, S. et al. Facile green synthesis of crystalline polyimide photocatalyst for hydrogen generation from water. J. Mater. Chem. 22, doi:10.1039/c2jm32595k (2012).

93 Jiang, J.-X. et al. Conjugated Microporous Poly(aryleneethynylene) Networks. Angew. Chem. Int. Ed. 46, 8574-8578, doi:doi:10.1002/anie.200701595 (2007).

94 Sprick, R. S. et al. Extended conjugated microporous polymers for photocatalytic hydrogen evolution from water. Chem. Commun. 52, 10008-10011, doi:10.1039/C6CC03536A (2016).

95 Bhunia, A. et al. A photoluminescent covalent triazine framework: $\mathrm{CO} 2$ adsorption, lightdriven hydrogen evolution and sensing of nitroaromatics. J. Mater. Chem. A 4, 13450-13457, doi:10.1039/C6TA04623A (2016).

96 Xu, Y. et al. Perylene-Containing Conjugated Microporous Polymers for Photocatalytic Hydrogen Evolution. Macromol. Chem. Phys. 218, 1700049, doi:doi:10.1002/macp.201700049 (2017).

$97 \mathrm{Xu}, \mathrm{Y}$. et al. Tetra-armed conjugated microporous polymers for gas adsorption and photocatalytic hydrogen evolution. Sci. China Chem. 60, 1075-1083, doi:10.1007/s11426017-9077-0 (2017).

98 Chaoui, N., Trunk, M., Dawson, R., Schmidt, J. \& Thomas, A. Trends and challenges for microporous polymers. Chem. Soc. Rev. 46, 3302-3321, doi:10.1039/C7CS00071E (2017).

99 Li, L. \& Cai, Z. Structure control and photocatalytic performance of porous conjugated polymers based on perylene diimide. Polym. Chem. 7, 4937-4943, doi:10.1039/C6PY00972G (2016).

100 Wang, L. et al. Photocatalytic oxygen evolution from low-bandgap conjugated microporous polymer nanosheets: a combined first-principles calculation and experimental study. Nanoscale 9, 4090-4096, doi:10.1039/C7NR00534B (2017).

101 Wang, L., Zheng, X., Chen, L., Xiong, Y. \& Xu, H. Van der Waals Heterostructures Comprised of Ultrathin Polymer Nanosheets for Efficient Z-Scheme Overall Water Splitting. Angew. Chem. Int. Ed. 130, 3512-3516, doi:doi:10.1002/ange.201710557 (2018).

102 Jiang, J.-X. et al. Conjugated microporous poly(phenylene butadiynylene)s. Chem. Commun., 486-488, doi:10.1039/B715563H (2008).

103 Côté, A. P. et al. Porous, Crystalline, Covalent Organic Frameworks. Science 310, 1166-1170, doi:10.1126/science.1120411 (2005).

104 Vyas, V. S. et al. A tunable azine covalent organic framework platform for visible lightinduced hydrogen generation. Nat. Comm. 6, 8508, doi:10.1038/ncomms9508 (2015).

105 Banerjee, T. et al. Single-Site Photocatalytic H2 Evolution from Covalent Organic Frameworks with Molecular Cobaloxime Co-Catalysts. J. Am. Chem. Soc. 139, 16228-16234, doi:10.1021/jacs.7b07489 (2017). 
106 Pachfule, P. et al. Diacetylene Functionalized Covalent Organic Framework (COF) for Photocatalytic Hydrogen Generation. J. Am. Chem. Soc. 140, 1423-1427, doi:10.1021/jacs.7b11255 (2018).

107 Wang, X. et al. Sulfone-containing covalent organic frameworks for photocatalytic hydrogen evolution from water. Nat. Chem. 10, 1180-1189, doi:10.1038/s41557-018-0141-5 (2018).

108 Bai, Y. et al. Accelerated Discovery of Organic Polymer Photocatalysts for Hydrogen Evolution from Water through the Integration of Experiment and Theory. J. Am. Chem. Soc. 141, 9063-9071, doi:10.1021/jacs.9b03591 (2019).

109 Guiglion, P., Butchosa, C. \& Zwijnenburg, M. A. Polymeric watersplitting photocatalysts; a computational perspective on the water oxidation conundrum. J. Mater. Chem. A 2, 1199612004, doi:10.1039/c4ta02044h (2014).

110 Butchosa, C., Guiglion, P. \& Zwijnenburg, M. A. Carbon Nitride Photocatalysts for Water Splitting: A Computational Perspective. J. Phys. Chem. C 118, 24833-24842, doi:10.1021/jp507372n (2014).

111 Merschjann, C. et al. Photophysics of polymeric carbon nitride: An optical quasimonomer. Phys. Rev. B 87, 205204 (2013).

112 Godin, R., Wang, Y., Zwijnenburg, M. A., Tang, J. \& Durrant, J. R. Time-Resolved Spectroscopic Investigation of Charge Trapping in Carbon Nitrides Photocatalysts for Hydrogen Generation. J. Am. Chem. Soc. 139, 5216-5224, doi:10.1021/jacs.7b01547 (2017).

113 Merschjann, C. et al. Complementing Graphenes: 1D Interplanar Charge Transport in Polymeric Graphitic Carbon Nitrides. Adv. Mater. 27, 7993-7999, doi:10.1002/adma.201503448 (2015).

114 Corp, K. L. \& Schlenker, C. W. Ultrafast Spectroscopy Reveals Electron-Transfer Cascade That Improves Hydrogen Evolution with Carbon Nitride Photocatalysts. J. Am. Chem. Soc., doi:10.1021/jacs.7b02869 (2017).

115 Nogueira, A. F. et al. Charge Recombination in Conjugated Polymer/Fullerene Blended Films Studied by Transient Absorption Spectroscopy. J. Phys. Chem. B 107, 1567-1573, doi:10.1021/jp027101z (2003).

116 Baxter, J. B., Richter, C. \& Schmuttenmaer, C. A. Ultrafast Carrier Dynamics in Nanostructures for Solar Fuels. Annu. Rev. Phys. Chem. 65, 423-447, doi:doi:10.1146/annurev-physchem-040513-103742 (2014).

117 Wang, H. et al. Boosting Hot-Electron Generation: Exciton Dissociation at the OrderDisorder Interfaces in Polymeric Photocatalysts. J. Am. Chem. Soc. 139, 2468-2473, doi:10.1021/jacs.6b12878 (2017).

118 Walsh, J. J., Jiang, C., Tang, J. \& Cowan, A. J. Photochemical CO2 reduction using structurally controlled g-C3N4. Phys. Chem. Chem. Phys. 18, 24825-24829, doi:10.1039/C6CP04525A (2016).

119 Kuriki, R. et al. Nature-Inspired, Highly Durable CO2 Reduction System Consisting of a Binuclear Ruthenium(II) Complex and an Organic Semiconductor Using Visible Light. J. Am. Chem. Soc. 138, 5159-5170, doi:10.1021/jacs.6b01997 (2016).

120 Kasap, H. et al. Solar-Driven Reduction of Aqueous Protons Coupled to Selective Alcohol Oxidation with a Carbon Nitride-Molecular Ni Catalyst System. J. Am. Chem. Soc. 138, 91839192, doi:10.1021/jacs.6b04325 (2016). 
121 Moon, G.-h. et al. Eco-Friendly Photochemical Production of $\mathrm{H} 2 \mathrm{O} 2$ through $\mathrm{O} 2$ Reduction over Carbon Nitride Frameworks Incorporated with Multiple Heteroelements. ACS Catal. 7, 2886-2895, doi:10.1021/acscatal.6b03334 (2017).

122 Peng, G., Albero, J., Garcia, H. \& Shalom, M. A Water-Splitting Carbon Nitride Photoelectrochemical Cell with Efficient Charge Separation and Remarkably Low Onset Potential. Angew. Chem. Int. Ed. 130, 16033-16037, doi:10.1002/ange.201810225 (2018).

123 Zhang, W. et al. One-Pot Synthesis of Nickel-Modified Carbon Nitride Layers Toward Efficient Photoelectrochemical Cells. ACS Appl. Mater. Interfaces 9, 32667-32677, doi:10.1021/acsami.7b08022 (2017).

124 Jing, L., Zhu, R., Phillips, D. L. \& Yu, J. C. Effective Prevention of Charge Trapping in Graphitic Carbon Nitride with Nanosized Red Phosphorus Modification for Superior Photo(electro)catalysis. Adv. Funct. Mater. 27, doi:10.1002/adfm.201703484 (2017).

125 Elbanna, O., Fujitsuka, M. \& Majima, T. g-C3N4/TiO2 Mesocrystals Composite for H2 Evolution under Visible-Light Irradiation and Its Charge Carrier Dynamics. ACS Appl. Mater. Interfaces 9, 34844-34854, doi:10.1021/acsami.7b08548 (2017).

126 Lau, V. W.-h. et al. Dark Photocatalysis: Storage of Solar Energy in Carbon Nitride for TimeDelayed Hydrogen Generation. Angew. Chem. Int. Ed. 56, 510-514, doi:10.1002/anie.201608553 (2017).

127 Savateev, A., Kurpil, B., Mishchenko, A., Zhang, G. \& Antonietti, M. A "waiting" carbon nitride radical anion: a charge storage material and key intermediate in direct $\mathrm{C}-\mathrm{H}$ thiolation of methylarenes using elemental sulfur as the "S"-source. Chem. Sci. 9, 3584-3591, doi:10.1039/C8SC00745D (2018).

128 Pellegrin, Y. \& Odobel, F. Sacrificial electron donor reagents for solar fuel production. Comptes Rendus Chimie 20, 283-295, doi:https://doi.org/10.1016/j.crci.2015.11.026 (2017).

129 Matsuoka, S. et al. Photocatalysis of oligo (p-phenylenes): photoreductive production of hydrogen and ethanol in aqueous triethylamine. The Journal of Physical Chemistry 95, 58025808 (1991).

130 Yanagida, S. et al. Synthesis of $2,^{\prime}: 5^{\prime}, 2^{\prime \prime}$-terpyridine and $2,2^{\prime}: 5^{\prime}, 2^{\prime \prime}: 5^{\prime \prime}, 2^{\prime \prime \prime}$-quaterpyridine and their photocatalysis of the reduction of water. J. Chem. Soc. Perkin Trans., 1963-1969, doi:10.1039/P29960001963 (1996).

131 Yanagida, S. \& Matsuoka, S. in Optical Materials Technology for Energy Efficiency and Solar Energy. 8 (SPIE).

132 Reynal, A., Lakadamyali, F., Gross, M. A., Reisner, E. \& Durrant, J. R. Parameters affecting electron transfer dynamics from semiconductors to molecular catalysts for the photochemical reduction of protons. Energy Environ. Sci. 6, 3291-3300, doi:10.1039/C3EE40961A (2013).

133 Rodenberg, A. et al. Mechanism of Photocatalytic Hydrogen Generation by a PolypyridylBased Cobalt Catalyst in Aqueous Solution. Inorg. Chem. 54, 646-657, doi:10.1021/ic502591a (2015).

134 Pastor, E. et al. Spectroelectrochemical analysis of the mechanism of (photo)electrochemical hydrogen evolution at a catalytic interface. Nat. Comm. 8, 14280, doi:10.1038/ncomms 14280 
https://www.nature.com/articles/ncomms14280\#supplementary-information (2017).

135 Pesci, F. M., Cowan, A. J., Alexander, B. D., Durrant, J. R. \& Klug, D. R. Charge Carrier Dynamics on Mesoporous WO3 during Water Splitting. J. Phys. Chem. Lett. 2, 1900-1903, doi:10.1021/jz200839n (2011).

136 Wang, X. et al. Transient Absorption Spectroscopy of Anatase and Rutile: The Impact of Morphology and Phase on Photocatalytic Activity. J. Phys. Chem. C 119, 10439-10447, doi:10.1021/acs.jpcc.5b01858 (2015).

137 Sachs, M. et al. Understanding structure-activity relationships in linear polymer photocatalysts for hydrogen evolution. Nat. Comm. 9, 4968, doi:10.1038/s41467-018-074206 (2018).

138 Schwarze, M. et al. Quantification of photocatalytic hydrogen evolution. Phys. Chem. Chem. Phys. 15, 3466-3472, doi:10.1039/C3CP50168J (2013).

139 Le, C. C. et al. A General Small-Scale Reactor To Enable Standardization and Acceleration of Photocatalytic Reactions. ACS Cent. Sci. 3, 647-653, doi:10.1021/acscentsci.7b00159 (2017).

140 Kisch, H. \& Bahnemann, D. Best Practice in Photocatalysis: Comparing Rates or Apparent Quantum Yields? J. Phys. Chem. Lett. 6, 1907-1910, doi:10.1021/acs.jpclett.5b00521 (2015).

141 Han, L., Lin, M. \& Haussener, S. Reliable Performance Characterization of Mediated Photocatalytic Water-Splitting Half Reactions. ChemSusChem 10, 2158-2166, doi:10.1002/cssc.201601901 (2017).

142 Ehrmaier, J., Janicki, M. J., Sobolewski, A. L. \& Domcke, W. Mechanism of photocatalytic water splitting with triazine-based carbon nitrides: insights from ab initio calculations for the triazine-water complex. Phys. Chem. Chem. Phys., doi:10.1039/c8cp01998c (2018).

143 Godin, R., Kafizas, A. \& Durrant, J. R. Electron transfer dynamics in fuel producing photosystems. Curr. Opin. Electrochem. 2, 136-143, doi:http://doi.org/10.1016/j.coelec.2017.03.012 (2017).

144 Ferreira, K. N., Iverson, T. M., Maghlaoui, K., Barber, J. \& Iwata, S. Architecture of the Photosynthetic Oxygen-Evolving Center. Science 303, 1831-1838, doi:10.1126/science.1093087 (2004).

145 Zhang, J. et al. Photocatalytic oxidation of water by polymeric carbon nitride nanohybrids made of sustainable elements. Chem. Sci. 3, 443-446, doi:10.1039/C1SC00644D (2012).

146 Wang, W., Jimmy, C. Y., Shen, Z., Chan, D. K. \& Gu, T. gC 3 N 4 quantum dots: direct synthesis, upconversion properties and photocatalytic application. Chem. Commun. 50, 10148-10150, doi:10.1039/C4CC02543A (2014).

147 Kang, Y. et al. An Amorphous Carbon Nitride Photocatalyst with Greatly Extended VisibleLight-Responsive Range for Photocatalytic Hydrogen Generation. Adv. Mater. 27, 4572-4577 (2015).

148 Yang, P., Ou, H., Fang, Y. \& Wang, X. A Facile Steam Reforming Strategy to Delaminate Layered Carbon Nitride Semiconductors for Photoredox Catalysis. Angew. Chem. Int. Ed. 56, 3992-3996, doi:doi:10.1002/anie.201700286 (2017).

149 Ou, H. et al. Tri-s-triazine-Based Crystalline Carbon Nitride Nanosheets for an Improved Hydrogen Evolution. Adv. Mater. 29, 1700008, doi:doi:10.1002/adma.201700008 (2017). 
150 Aitchison, Catherine M., Sprick, R. S. \& Cooper, A. I. Emulsion polymerization derived organic photocatalysts for improved light-driven hydrogen evolution. J. Mater. Chem. A 7, 24902496, doi:10.1039/C8TA11383A (2019).

151 Vogel, A. et al. Photocatalytically active ladder polymers. Faraday Discuss., doi:10.1039/C8FD00197A (2019).

152 Zong, X. et al. Structure defects assisted photocatalytic $\mathrm{H} 2$ production for polythiophene nanofibers. Appl. Catal., B 211, 98-105, doi:10.1016/j.apcatb.2017.04.033 (2017).

$153 \mathrm{Xie}, \mathrm{J}$. et al. Efficient visible light-driven water oxidation and proton reduction by an ordered covalent triazine-based framework. Energy Environ. Sci., doi:10.1039/C7EE02981K (2018).

154 Sprick, R. S. et al. Photocatalytic Hydrogen Evolution from Water Using Fluorene and Dibenzothiophene Sulfone-Conjugated Microporous and Linear Polymers. Chem. Mater. 31, 305-313, doi:10.1021/acs.chemmater.8b02833 (2019). 